\title{
A Sensitivity Study of Hodograph-Based Methods for Estimating Supercell Motion
}

\author{
HAMish A. RAMSAY \\ Cooperative Institute for Mesoscale Meteorological Studies, and School of Meteorology, University of Oklahoma, Norman, Oklahoma \\ Charles A. Doswell III \\ Cooperative Institute for Mesoscale Meteorological Studies, University of Oklahoma, Norman, Oklahoma
}

(Manuscript received 28 January 2005, in final form 10 May 2005)

\begin{abstract}
Four supercell motion forecast algorithms are investigated with respect to their hodograph-analysis parameters. Another method derived from the data presented herein, the so-called offset method, is used to develop a baseline standard for the aforementioned schemes, using the observed storm motions and the mean wind. It is not a forecast scheme, as it is based on knowing the observed storm motions. This work explores the sensitivity of these algorithms to their arbitrary parameters by systematically varying those parameters, using a dataset of 394 right-moving supercells, and associated proximity soundings. The parameters used in these algorithms to define the layer depths for advection and/or propagation of supercells have not been shown to be optimum for this purpose. These arbitrary parameters compose the top and bottom levels of the mean wind layer, and a deviation vector from the mean wind defined through that layer. Two of the most recently developed algorithms have also implemented the vertical wind shear vector over an arbitrary layer depth. It has been found that, among other results, the scheme using both mean wind and vertical wind shear is more sensitive to the depth of the mean wind layer than it is to the depth of the vertical wind shear layer. It has also been shown that, when using the simplest schemes, the most accurate forecasts, on average, are obtained by using deep mean wind layers (i.e., greater than $0-10 \mathrm{~km}$ ). Indeed, all the forecast schemes show a strong tendency for the $u$ component of the predicted storm motion to be regulated by the depth of the mean wind layer. The $v$ component of the prediction storm motion, on the other hand, appears to be controlled by the deviation vector from the layer-mean wind. Although the schemes using vertical shear are shown to perform somewhat better on average than schemes based on the mean wind alone, there are times in which they also result in large forecast errors. The results demonstrate the inherent difficulty in using an observed hodograph to predict supercell motion.
\end{abstract}

\section{Introduction}

\section{a. Background}

A "supercell" is defined as a thunderstorm containing a deep, persistent, mesocyclone (Doswell and Burgess 1993). Accurate forecasts of supercell motion are important, since supercells are often accompanied by hazardous weather such as tornadoes, flash flooding, large hail, and damaging wind gusts. Of additional importance is the application of supercell motion forecasts to the calculation of severe weather storm-relative parameters, used frequently by severe weather forecast-

Corresponding author address: Hamish A. Ramsay, CIMMS, University of Oklahoma, Sarkeys Energy Center, Rm. 1011, 100 E. Boyd St., Norman, OK 73019-1011.

E-mail: hramsay@rossby.metr.ou.edu ers. For example, since the mid-1980s, supercell motion estimates have been incorporated in the computation of storm-relative helicity (Davies-Jones 1984; Droegemeier et al. 1993) and storm-relative winds (Brooks et al. 1994).

For the past 50 years, proximity soundings have been used extensively to identify environmental parameters associated with a variety of severe weather phenomena (e.g., Beebe 1958; Darkow 1969; Brooks et al. 1994; Rasmussen and Blanchard 1998; Thompson 1998; Evans and Doswell 2001). Early observational and theoretical studies (Browning 1964, 1965a,b) gave much attention to the nature of so-called right-moving supercells: that is, supercells with motion to the right of the mean wind. Several years later, numerical modeling work (Rotunno and Klemp 1982; Weisman and Klemp 1984) showed how clockwise turning of the environ- 
mental hodograph with height favors right-moving storms, whereas counterclockwise turning of the hodograph favors left-moving storms. It also has been shown observationally that most supercells in the United States are right moving, apparently because the vertical wind shear vector typically veers (turns clockwise) with height (Maddox 1976). Though left-moving supercells can produce severe hail and wind damage, they produce tornadoes (e.g., Monteverdi et al. 2001) at a much lower frequency than their right-moving counterparts.

A simple supercell motion-forecasting scheme was developed by Maddox (1976) based on the hodographs of proximity soundings. Since then, several other algorithms of varying complexity have been offered (Colquhoun 1980; Davies and Johns 1993; Davies 1998; Rasmussen and Blanchard 1998; Bunkers et al. 2000). These supercell motion algorithms are used widely by the operational forecasting community and by those involved in numerical weather prediction.

\section{b. Supercell motion forecast schemes}

Maddox (1976, hereafter M76) analyzed 159 tornado proximity soundings ${ }^{1}$ that he defined to be within 92.5 $\mathrm{km}$ of a verified tornado that occurred between 1600 and 1900 central standard time (CST). Sounding release time was typically around 1715 CST. The mean wind vector for each sounding was computed by taking the average of the observed wind components at the surface (SFC) and 850-, 700-, 500-, 300-, and 200-hPa mandatory pressure levels. Having considered previous studies concerning deviate severe storm motions (Marwitz 1972; Fankhauser 1971), Maddox estimated the average motion of a right-moving supercell to be at $30^{\circ}$ to the right of the mean wind direction, and at $75 \%$ of the mean wind speed (hereafter, 30R75).

Colquhoun (1980, hereafter C80) estimated the velocity of severe storms by postulating that the most severe storms move to equalize the mass of air brought into the storm by the updraft and the downdraft. In particular, the C80 scheme assumes that 1) the air brought into the storm by the updraft is balanced by the air brought out of the storm by the downdraft, 2) the downdraft has an upper limit of $450 \mathrm{hPa}, 3$ ) maximum storm intensity is reached when it moves with the motion giving the maximum rate of inflow into the storm, and 4) in a storm-relative framework, the updraft approaches from the front and the downdraft from the rear. The algorithm requires a first-guess estimate of storm motion, generally a layer-mean wind, from which

\footnotetext{
${ }^{1}$ It is assumed that most of these storms were supercells, although we cannot be categorically certain that all of them were.
}

a more accurate estimate can be obtained by using iteration to find the velocity that gives balanced flow between the updraft and downdraft. The pressure level that separates the updraft source layer from the downdraft source layer is assumed constant, though no value for this is given. The method was originally tested using a sample of 10 subjectively interpolated severe thunderstorm proximity soundings, and storm motion errors were averaged and partitioned into a mean directional error and a mean vector error magnitude (hereafter MVE).

Davies and Johns (1993, hereafter DJ93) modified Maddox's method using a sample of 31 right-moving supercell proximity soundings. They did this by stratifying the storm motion according to the mean environmental wind speed in the 0-6 km AGL layer. For relatively strong mean wind environments (i.e., 0-6 km mean wind $>15 \mathrm{~m} \mathrm{~s}^{-1}$ ), it was found that the storms moved on average at $20^{\circ}$ to the right of the mean wind, and at $85 \%$ of the mean wind speed. Similarly, for environments characterized by weaker mean winds (i.e., 0-6 km mean wind $\leq 15 \mathrm{~m} \mathrm{~s}^{-1}$ ), the storms moved closer to 30R75, as originally proposed by Maddox.

Davies (1998) extended DJ93 by including supercells in environments where the $0-6 \mathrm{~km}$ mean wind was less than $10 \mathrm{~m} \mathrm{~s}^{-1}$. A sample of twenty-three 12 -h forecast proximity soundings was examined, and it was found that the observed storm motion was generally far to the right of the $0-6 \mathrm{~km}$ mean wind, with more than $30^{\circ}$ in directional deviation. Thus, the 30R75 method was deemed inappropriate for such weak wind environments. As an alternative, a "sliding scale" algorithm was suggested in which the $0-6 \mathrm{~km}$ mean wind was partitioned into three speed divisions: 1) $\geq 15$, 2) 10-14, and 3) 5-9 $\mathrm{m} \mathrm{s}^{-1}$. The corresponding storm motion estimates ranged from 20R80 for greater mean wind speeds $\left(\geq 15 \mathrm{~m} \mathrm{~s}^{-1}\right)$, to $80 \mathrm{R} 60$ for lesser mean wind speeds $\left(5-9 \mathrm{~m} \mathrm{~s}^{-1}\right)$.

Rasmussen and Blanchard (1998, hereafter RB98) developed an algorithm based on 45 supercell proximity soundings. Forecast storm motion was estimated at $8.6 \mathrm{~m} \mathrm{~s}^{-1}$ orthogonal and to the right of the tip of the $0.6 \mathbf{S}$ vector, where $\mathbf{S}$ is the vertical wind shear vector from the mean wind within the boundary layer (hereafter BL, which they defined to be the lowest $500 \mathrm{~m}$ ), to $4 \mathrm{~km}$. Unlike other methods discussed thus far, this method is Galilean invariant. Consequently, the RB98 scheme predicts the same shear-relative forecast motion, regardless of where the hodograph lies with respect to the origin.

Most recently, Bunkers et al. (2000) have developed the so-called Internal Dynamics method (hereafter the "Bunkers scheme") for predicting supercell motion. 
Like RB98, the technique is Galilean invariant, and is based partly on the modeling work done by Rotunno and Klemp $(1982,1985)$. Rotunno and Klemp demonstrated that enhanced vertical motion, attributable to shear-induced vertical pressure gradients, is found to the right of the vertical wind shear vector for clockwiseturning hodographs. As a result, the physical basis of the algorithm is predicated on the notion, common to all schemes considered, that supercell motion has both advection and propagation components. Using a dataset of 130 right-moving supercells, Bunkers found that the method yielded the lowest MVE when the following parameters were used: 1) a 0-6 km mean wind (or $0-8 \mathrm{~km}$ if pressure weighting was used), 2) an orthogonal deviation from the $0-6 \mathrm{~km}$ mean wind of 7.5 $\left.\mathrm{m} \mathrm{s}^{-1}, 3\right)$ a $5.5-6 \mathrm{~km}$ average wind for the head of the vertical wind shear vector, and 4) a $0-500 \mathrm{~m}$ average wind for the tail of the vertical wind shear vector. The Bunkers scheme has been used widely, and on 21 April 2000, the National Centers for Environmental Prediction (NCEP) incorporated this algorithm into their storm-relative helicity calculations.

\section{c. Motivation for the current study}

All supercell motion forecast schemes of which we are aware depend on some combination of wind profile-related variables. These variables, in turn, use arbitrary parameters: the top and bottom levels of the mean wind layer, the top and bottom levels of the vertical wind shear layer, and some constant deviation vector. The arbitrary nature of these parameters should be a concern to the forecaster, owing to possible sensitivities associated with them. The atmospheric environment of a supercell is neither constant in time nor in space, so the environment in which a storm exists can vary widely from one case to another, as well as during the life of any particular storm (Markowski et al. 1998).

The sensitivity of the motion estimates to these arbitrary parameters is the primary issue to be explored in the current study. A secondary objective is to test whether information from a sounding, namely the lifting condensation level (LCL), the level of free convection (LFC), and the equilibrium level (EL), could be used effectively to define the top and bottom level of the mean wind and/or shear layer, and thereby reduce the arbitrary nature of those parameters. Finally, the relationship between the observed median storm motion and layer-mean wind is investigated. Because all the schemes are based on the notion that the observed motion combines an advective component and a propagation component, the mean wind can be regarded as pertinent to the advective component and the difference between the mean wind and the observed motion is associated with an "offset" that can be regarded as pertinent to the propagation component. We observe that the storm motion estimates using any of these schemes include both dispersion and bias errors. The offset method was developed to define a baseline storm motion estimate that exploits the fact that observed storm motions were known beforehand. Therefore, the offset method is not proposed herein as an operational forecast scheme.

\section{Data}

The observed supercell motions for all cases were provided by M. Bunkers (2002, personal communication), and were estimated by tracking the centroid of the radar echo for a period of about $1 \mathrm{~h}$, during the most mature phase of development (or in some cases, the tornadic phase). For most cases, an automated mesocyclone detection algorithm (Stumpf et al. 1998) was used to determine whether a storm had supercell characteristics. The algorithm includes information on the horizontal wind shear, the depth of the circulation, and its temporal continuity. As an added precaution, most of the radar-observed supercells were of an isolated nature, so that their identity remained intact and problems associated with interactions between neighboring storms could be avoided (M. Bunkers 2003, personal communication).

Our basic dataset consists of 524 right-moving supercell proximity soundings and radar-observed storm motions, extending from 1958 to 2002, and covering a large area of the continental United States. These were partitioned into two sets of data: 1) a reference dataset comprising the 130 cases used by Bunkers et al. (2000) to develop his scheme, and 2) a new dataset comprising 394 cases (hereafter referred to as the "new dataset"). Of these 394 cases, 283 were collected by M. Bunkers [National Weather Service (hereafter NWS)], 34 were provided to him by R. Thompson [NWS Storm Prediction Center (hereafter SPC)], 44 by R. Edwards (SPC), and 7 by J. Davies. An additional 26 cases came directly from the literature (Brown 1993). The mean hodograph for the new dataset is shown in Fig. 1, along with the mean observed storm motion. It should be noted that the observed storm motions and associated proximity soundings used to compile the new dataset were part of a larger dataset provided by M. Bunkers. However, unlike the reference dataset, only observations from a single sounding site were selected. This restriction was imposed to eliminate the uncertainty of interpolating between observations.

Given that all the data were provided by M. Bunkers, the criteria used to define "proximity" were essentially 


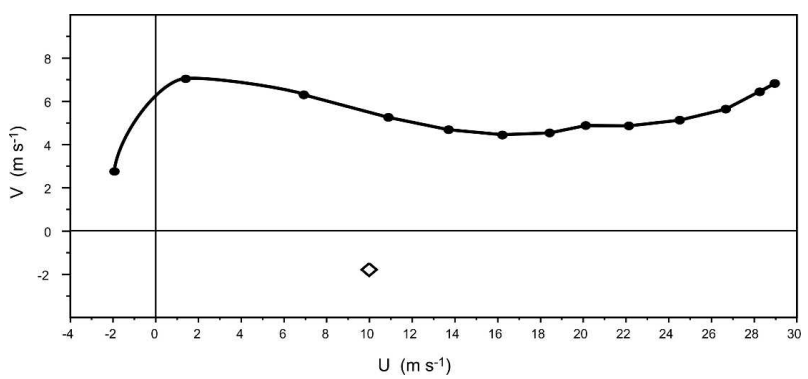

FIG. 1. Composite right-moving supercell hodograph (0-12 km) for all 394 cases in the new dataset. Vertical increments are $1 \mathrm{~km}$ (solid circles), and mean observed storm motion vector $(u=10.0$, $v=-1.8)$ is indicated by the diamond.

the same as Bunkers et al. (2000) and Thompson (1998). These criteria are relatively arbitrary, and the problem of trying to identify a representative sounding is complicated by the fact that a large degree of temporal and spatial variability exists within severe storm environments (Weisman et al. 1998). As Brooks et al. (1994) point out, "the idea of searching for proximity soundings implicitly recognizes that the environment in which an event occurs is not horizontally homogeneous. That is, the spatial variation is assumed to be large enough that an event really needs to be rather close to the sounding release point if the 'real' storm environment is to be sampled ..." The challenges associated with this issue are underscored by Markowski and Richardson (2004), who found that a high degree of spatial variability can exist within the $0-2 \mathrm{~km}$ wind field. For example, the 0-2 km shear vector was observed to change orientation by as much as $70^{\circ}$ in a time period of only $9 \mathrm{~min}$. With these complexities in mind, an effort was made so that the soundings used herein were

(i) within $100 \mathrm{n} \mathrm{mi}(185.2 \mathrm{~km})$ of the supercell,

(ii) released within $\pm 3 \mathrm{~h}$ from the time of the supercell,

(iii) in the inflow region of the supercell,

(iv) uncontaminated by nearby convection, and

(v) uncontaminated by the passage of fronts and other boundaries.

Although we did not actually compile the dataset ourselves, the soundings used for the new dataset were manually inspected to check for the above criteria. We believe that at most only a few cases would not precisely match the criteria, and this should not materially affect the results. Both the new and the reference dataset were retrieved using the NSHARP sounding software (Hart and Korotky 1991), and outputted in the General Meteorological Package (GEMPAK) format (desJardins et al. 1991).

\section{Methodology}

\section{a. Sensitivity testing}

The M76 method's sensitivity to its parameters was evaluated by varying the angular deviation and fractional portion of mean wind speed, as well as the depth of the mean wind layer. For example, the fractional portion of the mean wind speed was varied from $50 \%$ to $100 \%$, and the depth of the mean wind layer was varied from $0-6$ to $0-12 \mathrm{~km}$. The mean wind velocity for each layer was calculated both with and without pressure weighting.

The C80 algorithm was tested by varying the upper limit of the mass-flux integral used to compute the mean wind. Storm motions were computed using the original upper limit of $450 \mathrm{hPa}$, as well as 500, 400, 350, 300, 250, and $200 \mathrm{hPa}$.

Following the work of M76, DJ93 partitioned the observed storm motions into two groups, according to whether the environmental 0-6 km mean wind (without pressure weighting) was (i) greater than $15 \mathrm{~m} \mathrm{~s}^{-1}$ or (ii) less than $15 \mathrm{~m} \mathrm{~s}^{-1}$. The proposition that supercells should deviate less than $30^{\circ}$ to the right of the $0-6 \mathrm{~km}$ mean wind when the mean wind speed averages more than $15 \mathrm{~m} \mathrm{~s}^{-1}$ was tested using the new dataset.

The RB98 algorithm was tested using a number of different values for the parameters: $\mathbf{S}$, the fractional length of $\mathbf{S}$, and the orthogonal deviation vector (D). The depth of the vertical wind shear layer was varied from BL to $3 \mathrm{~km}$ to BL to $8 \mathrm{~km}$ in 1-km increments. The fractional length of the vertical wind shear vector, calculated for each layer, was also varied from 0.2 to 1.0. Finally, the magnitude of the deviation vector (orthogonal and to the right of the shear vector) was modified using values ranging from 6 to $10 \mathrm{~m} \mathrm{~s}^{-1}$.

According to Bunkers et al. (2000), the velocity of a right-moving supercell can be estimated by

$$
\mathbf{V}_{\mathrm{RM}}=\mathbf{V}_{\text {mean }}+D\left(\frac{\frac{\partial \mathbf{V}}{\partial z} \times \mathbf{k}}{\left|\frac{\partial \mathbf{V}}{\partial z}\right|}\right),
$$

where $\mathbf{V}_{\text {mean }}$ is the mean wind vector, $\partial \mathbf{V} / \partial \mathbf{z}$ is the vertical wind shear vector, and $D$ is the magnitude of the deviation vector from the tip of the mean wind vector, which is assumed to be perpendicular and to the right of the vertical shear vector.

The sensitivity of the algorithm was explored by considering different values for the top and bottom levels of the mean wind layer, the top and bottom levels of the vertical wind shear layer, and $D$. For instance, the bottom of the mean wind layer was varied from the SFC to 
$2 \mathrm{~km}$ in 500-m increments, while the top was varied from 3 to $12 \mathrm{~km}$, in $1-\mathrm{km}$ increments. In addition to these arbitrary levels, the mean wind layer was also defined using the LCL, LFC, and EL. The scheme was tested with and without pressure weighting when calculating the mean wind. The vertical wind shear layer and $D$ were varied in a similar fashion. The errors associated with the hodograph-analysis parameters were then correlated with other environmental parameters, such as convective available potential energy (CAPE), to see if the algorithm had any bias toward a particular type of environment. However, no statistically significant correlations were found, and are not presented herein.

\section{b. The offset method}

The distribution of vector errors of a random vector variable can be decomposed into a bias vector, and a dispersion about that bias. Forecast errors of the four forecast schemes described above revealed varying amounts of bias and dispersion, depending on the choices made for the arbitrary parameters. Since the mean winds and the observed storm motions were known for our data, the so-called offset method was developed to establish a baseline estimate of storm motion that had zero bias. Thus, it forms a standard for estimating the skill of the four true forecast schemes.

If the layer-mean wind is used as an estimate of the advective component of storm motion, an offset between the median of the mean wind scatter and the median of the observed motion scatter can be determined. A preliminary analysis of the forecast errors in the other schemes has shown that a significant part of the total error is associated with the bias in the estimates. The bias associated with using the layer-mean wind alone can be computed easily by taking the median of the observed $(u, v)$ components of the storm motion minus the median of the layer-mean wind $(u, v)$ components-the so-called offset vector. The offset vector can then be used as a constant to displace each point in the set of layer-mean winds, resulting in a set of estimates having no bias but retaining the original dispersion error. The dispersions of each of the layermean winds, and associated offset vectors, were compared to see which resulted in the minimum median vector error (hereafter, MDVE). The variance of MDVEs associated with each wind layer-offset vector combination was also considered.

\section{c. Numerical and graphical analysis techniques}

Several numerical and graphical summary techniques were used to analyze the results for each storm motion scheme. Statistical measures included the MVE, MDVE, and interquartile range (Wilks 1995). Note that MDVE is included herein because it is resistant to any skewness in the distributions.

Although such summary measures convey useful information about the error distributions of each forecast scheme, by themselves they determine only part of the nature of the errors (Brooks and Doswell 1996). Accordingly, scatterplots were constructed to extract additional information. These scatterplots, presented herein, include $u$ and $v$ forecast error components, the deviation vector from the mean wind defined through systematically varied layers, and the relationship between the mean vector error and various hodographrelated parameters. The scatterplots allowed for easy visualization of features in the data such as clusters, trends, spread, and outliers.

\section{d. Kernel density estimation}

Kernel density estimation (KDE; Bowman and Azzalini 1997) is a nonparametric technique whereby a given density function (the kernel) is used to produce a smooth, continuous estimate of the true density of the empirical distribution. The kernel can take on a variety of forms: for example, a triangle, a rectangle, or a Gaussian curve. The simplest nonparametric density estimation technique is the familiar histogram. Histograms divide the range of data into intervals, or "bins," and the number of data points falling into each interval is counted. The main disadvantage of the histogram is that its bin width is arbitrary, and can lead to potentially misleading results. An additional problem is the issue of end points, such as the left edge of the first bin. The histogram is also discontinuous, as it uses a discontinuous kernel for its building block.

The KDE method effectively alleviates many of the problems associated with arbitrary binning choices for histograms, although the choice of bandwidth (which controls the smoothing) remains subjective. See Wand and Jones (1995, chapter 1) for a discussion of the KDE approach. In the current study, a Gaussian kernel was used to create and display the KDE, which is depicted in two dimensions as one or more closed curves that prescribe the probability of a random data point falling within its perimeter. Mathematically, the kernel density estimate for bivariate data can be expressed in the form

$$
\hat{f}\left(y_{1}, y_{2}\right)=\frac{1}{n} \sum_{i=1}^{n} \frac{1}{h_{1} h_{2}} w\left(\frac{y_{1}-y_{1 i}}{h_{1}}\right) w\left(\frac{y_{2}-y_{2 i}}{h_{2}}\right),
$$

where $n$ is the number of observations, $w(z)$ is the kernel function, $y_{1}$ and $y_{2}$ are the dimensional variables, $y_{1 \mathrm{i}}$ and $y_{2 \mathrm{i}}$ are the observations of $y_{1}$ and $y_{2}$, and $h_{1}, h_{2}$ are 
the independent bandwidths in each dimension. An optimum smoothing parameter was used to define $h_{l}$ and $h_{2}$, such that

$$
h_{1}=\hat{\sigma}_{1} n^{-1 / 6}, h_{2}=\hat{\sigma}_{2} n^{-1 / 6}
$$

where $\hat{\sigma}_{1}$ and $\hat{\sigma}_{2}$ are the sample standard deviations of $y_{1}$ and $y_{2}$, respectively. The Gaussian kernel function, $w(z)$, is simply

$$
w(z)=\frac{1}{\sqrt{2 \pi}} \exp \left(\frac{-z^{2}}{2}\right) \text { for }-\infty<z<\infty .
$$

Our results, in bivariate form, are depicted using the 75th percentile KDE contour; it encloses an area that includes data points within about 1.1 standard deviations from the mean [for a unit normal (Gaussian) distribution, one standard deviation corresponds to about $68 \%$ of the distribution]. When considering a distribution of errors, the size of the KDE contour is proportional to the degree of error dispersion, whereas its centroid position relative to the origin represents the bias of the error. Indeed, the KDE technique was found to be a powerful and effective tool. It allowed for a simple graphical summary of the empirical distributions (i.e., the scatterplots), and easy comparison of the dispersion and bias associated with each set of forecast errors. The KDE technique also made it possible for several distributions to be displayed and interpreted easily in the same plot.

\section{e. Statistical significance testing}

Formal statistical significance tests were performed on the error distributions, both within individual schemes, and between the schemes. The Wilcoxon signed-rank test, a classical nonparametric test that stems from the same family as the $t$ test, was chosen to evaluate the data. As the name suggests, the test statistic is based on ranks rather than the actual values of the data. It is designed to test the null hypothesis $\left(\mathrm{H}_{0}: M_{d}=\right.$ 0 ) that the population median of the paired differences $\left(M_{d}\right)$ of two samples is equal to zero. The alternative hypothesis $\left(\mathrm{H}_{\mathrm{A}}: M_{d} \neq 0\right)$ was accepted if the test statistic fell in the top or bottom $0.5 \%(\alpha=0.01)$ of the $Z$ distribution (it should be noted that an $\alpha$ level of 0.01 corresponds to a critical $Z$ score of \pm 2.575 for a twosided test). The value of $\alpha$ represents the probability of rejecting the null hypothesis falsely, given that it is true. Assumptions are that the paired differences are independent, and that they come from continuous distributions that are symmetric, each with the same center of symmetry. These are reasonable assumptions for the new dataset. The central limit theorem, which states that for large sample sizes the sum of independent ob- servations will have a Gaussian distribution, is applicable. In addition, lag-1 autocorrelations were less than 0.10 , which supports the assumption that the paired differences are independent. Finally, the Wilcoxon signedrank test's nonparametric property allows for more flexibility in the shape of the individual distributions, and is also resistant to outliers.

\section{Results}

\section{a. The Bunkers scheme}

Bunkers et al. (2000) found that for the reference dataset, the $0-6 \mathrm{~km}$ mean wind layer resulted in a minimum MVE of $4.1 \mathrm{~m} \mathrm{~s}^{-1}$. Our analysis of the reference dataset did not precisely reproduce this finding, but instead resulted in an MVE of $4.3 \mathrm{~m} \mathrm{~s}^{-1}$. This small discrepancy is apparently the consequence of differences in the vertical interpolation process from the raw sounding data. Bunkers et al. (2000) indicate that their post-1995 data were retrieved from the online archive provided by the Forecast Systems Laboratory (FSL). Those soundings then were interpolated into $500-\mathrm{m}$ intervals from the surface to $8 \mathrm{~km}$. A direct comparison between those data and the GEMPAK-interpolated data used herein revealed consistent discrepancies in the wind velocities for the same levels between the two interpolation schemes. Upon further investigation, it was found that for certain cases, the GEMPAK data contained more observational information than the FSL data. Interestingly, the results from the new dataset $d o$ agree precisely with the MVE associated with the $0-6-\mathrm{km}$ mean wind layer, as found in Bunkers et al. (2000).

The storm motion forecast errors in the Bunkers scheme were most sensitive to changes in the mean wind layer. A mean wind layer of less depth than $0-8$ $\mathrm{km}$ resulted in an underestimate of the $u$ component of motion, whereas a layer deeper than $0-8 \mathrm{~km}$ resulted in an overestimate (Fig. 2). The forecast $v$ component of motion proved to be more or less independent of the depth of the mean wind layer. The mean wind layer that yielded the lowest MDVE $\left(2.9 \mathrm{~m} \mathrm{~s}^{-1}\right)$, as well as the least bias, was $0-8 \mathrm{~km}$.

When pressure weighting was employed to calculate the mean wind, the variance in the $(u, v)$ error component bias decreased significantly, particularly between 0-6 and $0-10 \mathrm{~km}$ (Fig. 3). The MDVE ranged from 2.9 $\mathrm{m} \mathrm{s}^{-1}$ using a $0-12-\mathrm{km}$ mean wind layer, to $8.7 \mathrm{~m} \mathrm{~s}^{-1}$ using a $0-3-\mathrm{km}$ mean wind layer. The minimum MVE $\left(3.5 \mathrm{~m} \mathrm{~s}^{-1}\right)$ and MDVE $\left(2.9 \mathrm{~m} \mathrm{~s}^{-1}\right)$ were found using the $0-12-\mathrm{km}$ mean wind layer. This result is quite different from Bunkers et al. (2000), where the minimum MVE was found either using a $0-7$ or a $0-8 \mathrm{~km}$ pres- 


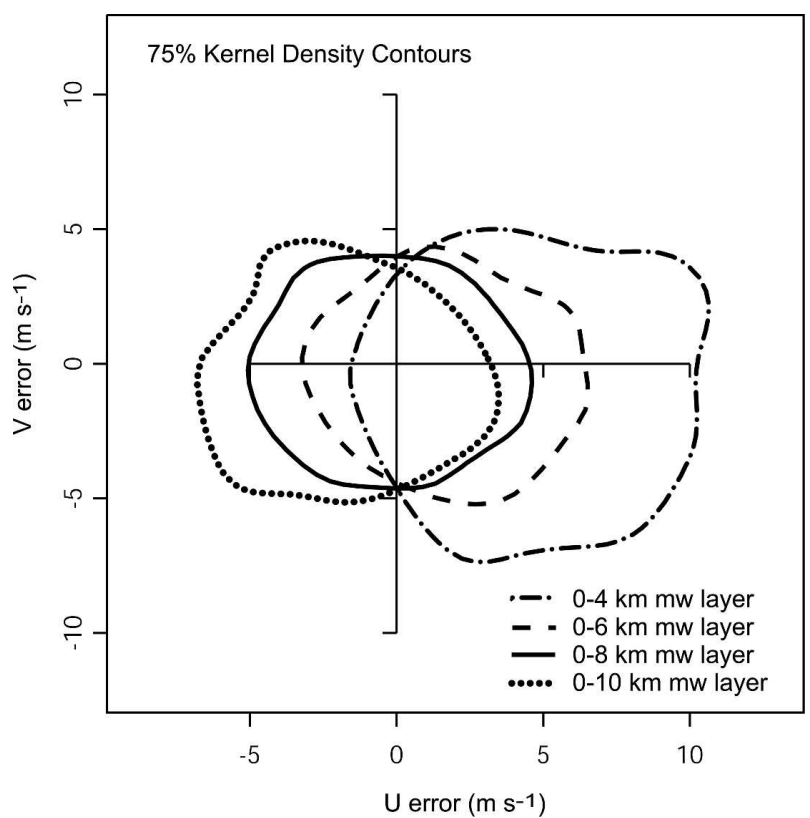

FIG. 2. KDE plot showing distribution of forecast vector errors for the $0-4,0-6,0-8$, and $0-10 \mathrm{~km}$ mean wind layers (without pressure weighting) in the Bunkers scheme. The shear layer is held constant from BL to 5.5-6 km. Deviation vector magnitude $(D)$ is $7.5 \mathrm{~m} \mathrm{~s}^{-1}$.

sure-weighted mean wind layer. In general, both the MDVE and $(u, v)$ error bias decreased as the depth of the mean wind layer increased (Fig. 3), where $(u, v)$ error bias is defined as the vector difference between the medians of the observed storm motion distribution and the forecast storm motion distribution. It was also found that the $0-12 \mathrm{~km}$ pressure-weighted mean wind layer and the $0-8 \mathrm{~km}$ mean wind layer without pressure weighting resulted in the same minimum MDVE.

As discussed above, the use of the $0-8 \mathrm{~km}$ mean wind (without pressure weighting) to estimate the storm motion resulted in the smallest MVE and MDVE when compared with the other wind layers, and further reduced the minimum error established in the original Bunkers scheme by $0.7 \mathrm{~m} \mathrm{~s}^{-1}$. Indeed, this result was highly statistically significant based on the Wilcoxon signed-rank test, at an $\alpha$ level of $0.01\left(\mathrm{H}_{\mathrm{A}}: M_{d} \neq 0, Z=\right.$ $7.356, p<0.00001)$. When compared head to head with the other mean wind layers, the $0-8 \mathrm{~km}$ mean wind accounted for the smallest vector error $17 \%$ of the time. Surprisingly, the $0-10 \mathrm{~km}$ mean wind layer most often led to the minimum errors ( $27 \%$ of all cases), even though it performed worse, on average, than the 0-7 to 0-9 km layers.

Finally, it was found that the inclusion of information other than the hodograph to define the top and bottom levels of the mean wind layer, such as the LCL and the $\mathrm{EL}$, offered no reduction in the forecast errors com-

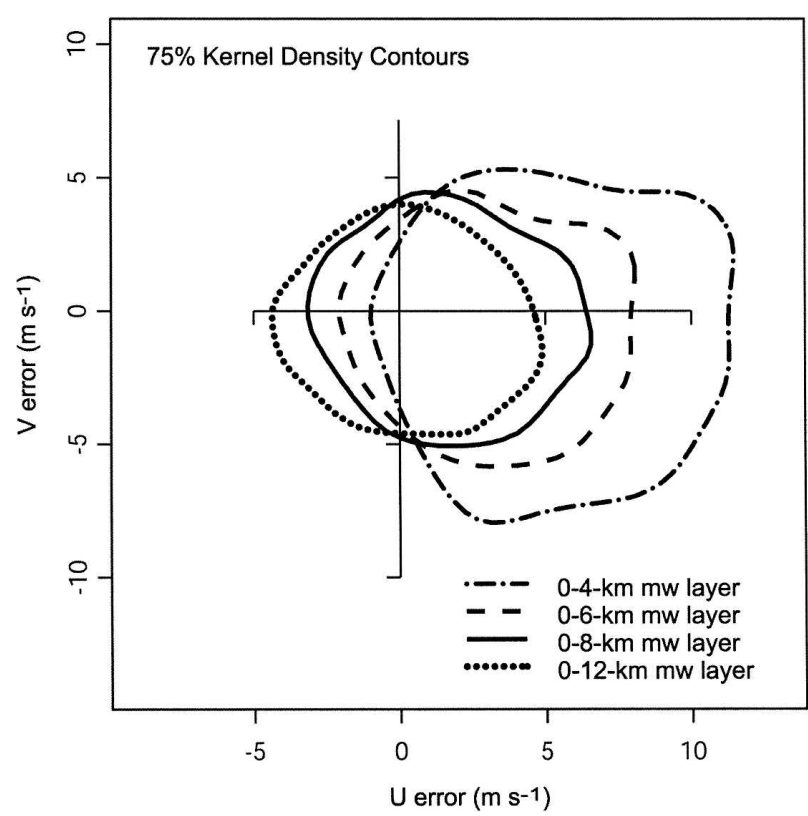

FIG. 3. KDE plot showing distribution of forecast vector errors for the $0-4,0-6,0-8$, and $0-12 \mathrm{~km}$ pressure-weighted mean wind layers in the Bunkers scheme. The shear layer is held constant from BL to $5.5-6 \mathrm{~km}$. Deviation vector magnitude $(D)$ is $7.5 \mathrm{~m} \mathrm{~s}^{-1}$.

pared to using arbitrary fixed layer depths (Table 1). The pressure-weighted SFC-EL mean wind layer resulted in the lowest MDVE $\left(3.1 \mathrm{~m} \mathrm{~s}^{-1}\right)$, which was only slightly larger than the minimum MDVEs associated with both the $0-8-\mathrm{km}$ layer without pressure weighting and $0-12 \mathrm{~km}$ pressure-weighted layers $\left(2.9 \mathrm{~m} \mathrm{~s}^{-1}\right)$. The similarity of the errors between the SFC-EL and $0-12 \mathrm{~km}$ layers was most likely the consequence of the average EL being close to $12 \mathrm{~km}$. Furthermore, the SFC-EL pressure-weighted layer resulted in substan-

TABLE 1. MVE, MDVE, and forecast bias associated with various fractional depths of the SFC-EL, LCL-EL, and LFC-EL pressure-weighted mean wind layers using the Bunkers scheme.

\begin{tabular}{lcccc}
\hline \hline $\begin{array}{c}\text { Mean wind } \\
\text { layer }\end{array}$ & $\begin{array}{c}\text { MVE } \\
\left(\mathrm{m} \mathrm{s}^{-1}\right)\end{array}$ & $\begin{array}{c}\text { MDVE } \\
\left(\mathrm{m} \mathrm{s}^{-1}\right)\end{array}$ & $\begin{array}{c}\text { Forecast bias } \\
\text { component } \\
\left(\mathrm{m} \mathrm{s}^{-1}\right)\end{array}$ & $\begin{array}{c}\text { Forecast bias } \\
v \text { component } \\
\left(\mathrm{m} \mathrm{s}^{-1}\right)\end{array}$ \\
\hline $1 / 4 \times$ SFC-EL & 10.1 & 9.9 & -7.6 & +1.1 \\
$1 / 2 \times$ SFC-EL & 5.8 & 5.0 & -3.6 & +0.7 \\
$3 / 4 \times$ SFC-EL & 4.2 & 3.5 & -1.7 & +0.6 \\
SFC-EL & 3.7 & 3.1 & -0.8 & +0.7 \\
$1 / 4 \times$ LCL-EL & 5.1 & 5.0 & -1.6 & +1.0 \\
$1 / 2 \times$ LCL-EL & 5.1 & 4.5 & +0.8 & +0.6 \\
$3 / 4 \times$ LCL-EL & 4.1 & 3.8 & +2.1 & +0.7 \\
LCL-EL & 4.5 & 4.3 & +2.9 & +0.7 \\
$1 / 4 \times$ LFC-EL & 4.8 & 4.3 & +0.4 & +0.5 \\
$1 / 2 \times$ LFC-EL & 5.0 & 4.6 & +2.4 & +0.4 \\
$3 / 4 \times$ LFC-EL & 5.8 & 5.3 & +3.9 & +0.4 \\
LFC-EL & 6.5 & 6.1 & +4.6 & +0.4 \\
\hline
\end{tabular}


tially less dispersion and bias than both the LCL-EL and LFC-EL mean wind layers (Fig. 4). Evidently, the Bunkers scheme results in more accurate forecasts for a mean wind layer that originates somewhere below the LCL, and preferably at the surface.

The layer depths through which the vertical wind shear is calculated were found to have the least effect on the bias and dispersion of the forecast errors (Fig. 5). Indeed, the MDVE remained almost constant for a wide range of vertical wind shear layers. The forecast errors are more sensitive to changes in the bottom of the vertical wind shear layer, given a constant top, rather than vice versa. This insensitivity to the vertical wind shear is evident in Fig. 1, which shows that the shear direction is relatively constant on the hodograph above about $1 \mathrm{~km}$. The lowest MDVE was found using vertical wind shear layers ranging from BL to $5.5-6 \mathrm{~km}$ to $\mathrm{BL}$ to $7.5-8 \mathrm{~km}$. Still, as evidenced in Table 2, the scheme is not sensitive to the height of the top of the layer above $4 \mathrm{~km}$, so long as the bottom is rooted somewhere between the surface and $500 \mathrm{~m}$. This finding agrees with that noted by Bunkers et al. (2000).

The magnitude of the deviation vector $(D)$ was found to play a large role in controlling the $v$ component of the forecast motion (Fig. 6). Apparently, this is due to the constraint in Eq. (1) that the deviation vector must be orthogonal and to the right of the vertical wind shear vector, which is typically oriented eastward. Apart from changes in the bias in the $v$ component of motion, Fig. 6 shows little variation in the dispersion. Accordingly, the storm motion errors were reduced by using $D$ values ranging between 7 and $9 \mathrm{~m} \mathrm{~s}^{-1}$. The lowest bias in both the $u$ and the $v$ components of motion was found

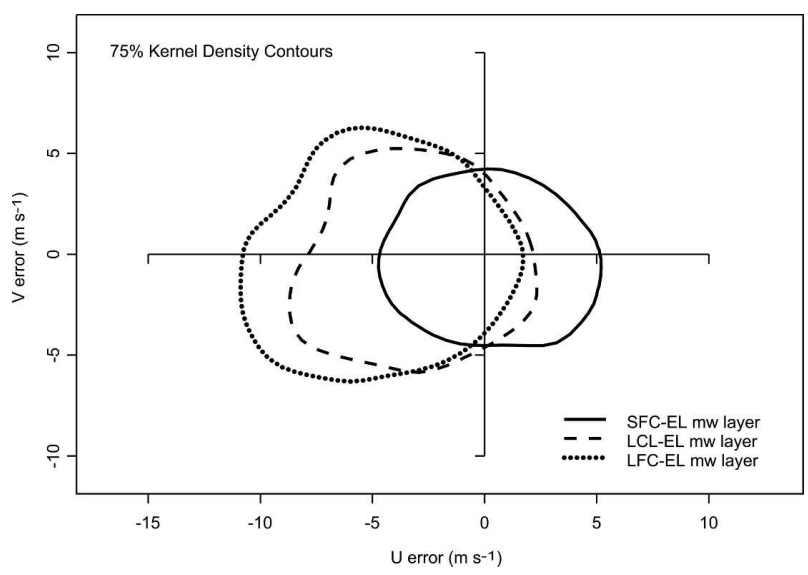

FIG. 4. KDE plot showing distribution of forecast vector errors using the SFC-EL, LCL-EL, and LFC-EL layers to define the pressure-weighted mean wind layer in the Bunkers scheme. The shear layer is held constant from BL to $5.5-6 \mathrm{~km}$. Deviation vector magnitude $(D)$ is $7.5 \mathrm{~m} \mathrm{~s}^{-1}$.

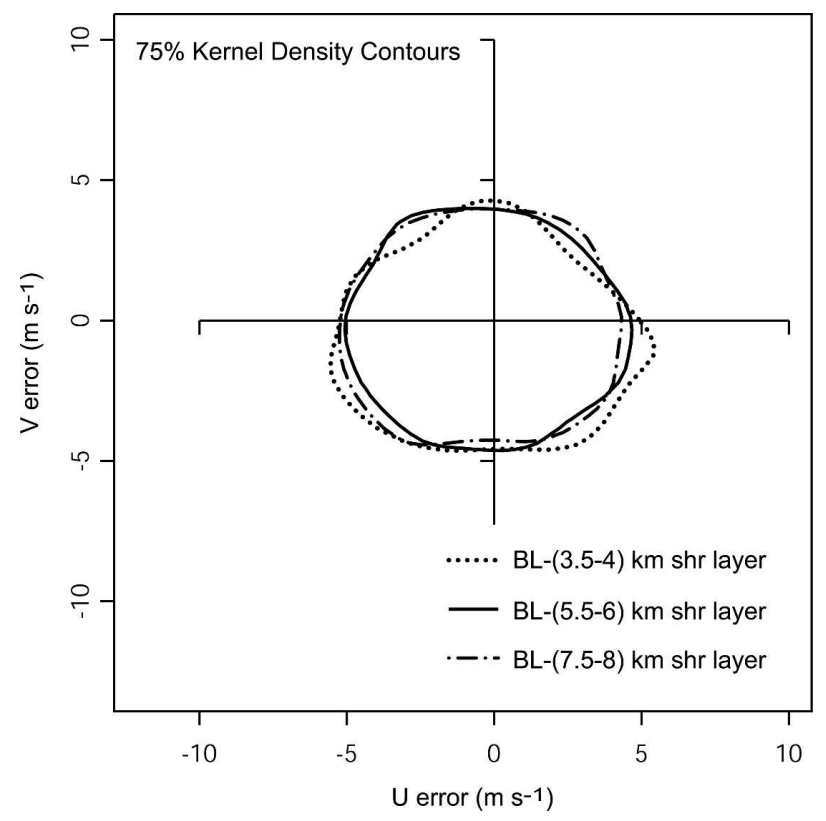

FIG. 5. KDE plot showing distribution of forecast vector errors using various vertical wind shear layers in the Bunkers scheme. The mean wind layer is held constant at $0-8 \mathrm{~km}$. Deviation vector magnitude $(D)$ is $7.5 \mathrm{~m} \mathrm{~s}^{-1}$.

using a $D$ of $8 \mathrm{~m} \mathrm{~s}^{-1}$. The minimum MDVE was associated with a $D$ of $7.5-8.0 \mathrm{~m} \mathrm{~s}^{-1}$, as proposed in the original Bunkers scheme.

\section{b. The RB98 scheme}

The depth of the vertical wind shear layer had a direct effect on both the MDVE and the bias in the $u$ component of the estimated motion. It was found that, for a given deviation vector, the BL-5 km and BL-6 km shear layers resulted in the lowest MDVE of $3.7 \mathrm{~m} \mathrm{~s}^{-1}$ (Table 3). In addition, the application of shear layers outside the range of BL-4 km to BL-6 km led to decreased accuracy (due to increased dispersion) in the forecasts, even when the $u-v$ bias was removed (Fig. 7). These results extend the work of RB98, in which only the BL-4 km bulk shear vector was considered.

The magnitude of the deviation vector essentially determined the $v$ component of the forecast motion, as illustrated in Fig. 8. Like the Bunkers scheme, the deviation vector was constrained to be perpendicular and to the right of the vertical wind shear vector, which is most often oriented eastward. It was found that a deviation vector of $7 \mathrm{~m} \mathrm{~s}^{-1}$ resulted in the minimum $(u$, $v$ ) error bias, as well as the minimum MDVE, when coupled with the BL-6 km bulk shear layer (Table 3). However, the combination of the BL-5 km bulk shear layer and a deviation vector of $7.5 \mathrm{~m} \mathrm{~s}^{-1}$ resulted in the 
TABLE 2. MDVE $\left(\mathrm{m} \mathrm{s}^{-1}\right)$ for various vertical shear layers, using a $0-8-\mathrm{km}$ mean wind, and a $7.5 \mathrm{~m} \mathrm{~s}^{-1}$ deviation vector magnitude $(D)$ in the Bunkers scheme.

\begin{tabular}{lllllllllll}
\hline \hline & \multicolumn{7}{c}{ Top of vertical wind shear layer } \\
\cline { 3 - 10 } & & $2.5-3 \mathrm{~km}$ & $3.5-4 \mathrm{~km}$ & $4.5-5 \mathrm{~km}$ & $5.5-6 \mathrm{~km}$ & $6.5-7 \mathrm{~km}$ & $7.5-8 \mathrm{~km}$ & $8.5-9 \mathrm{~km}$ & $9.5-10 \mathrm{~km}$ \\
\hline & SFC & 3.8 & 3.5 & 3.4 & 3.0 & 3.1 & 3.1 & 3.1 & 3.2 \\
Bottom of vertical wind shear layer & BL & 3.4 & 3.2 & 3.0 & 2.9 & 2.9 & 2.9 & 3.1 & 3.1 \\
& $1 \mathrm{~km}$ & 3.8 & 3.4 & 3.4 & 3.3 & 3.2 & 3.1 & 3.2 & 3.3 \\
& $2 \mathrm{~km}$ & 4.9 & 4.6 & 4.2 & 4.2 & 4.0 & 3.7 & 3.6 & 3.7 \\
& $3 \mathrm{~km}$ & $\mathrm{x}$ & 5.9 & 4.9 & 4.8 & 4.7 & 4.2 & 4.1 & 4.2 \\
\hline
\end{tabular}

least error dispersion, and also shared the minimum MDVE. The latter was therefore chosen as the optimum combination for this scheme. The range in the deviation vector that led to the optimum forecast differed somewhat from that used in RB98, in which their best empirical fit to the storm motions was obtained using a deviation vector of $8.6 \mathrm{~m} \mathrm{~s}^{-1}$.

\section{c. The M76 scheme}

A wide range of M76 scheme forecast deviant storm motions was found, depending on the depth of the mean wind layer, using the same simple classification scheme as originally proposed by Maddox (1976). For example, a motion of $30 \mathrm{R} 75$ resulted in the minimum MDVE when a $0-10 \mathrm{~km}$ mean wind was employed (Table 4). However, when the mean wind was calcu-

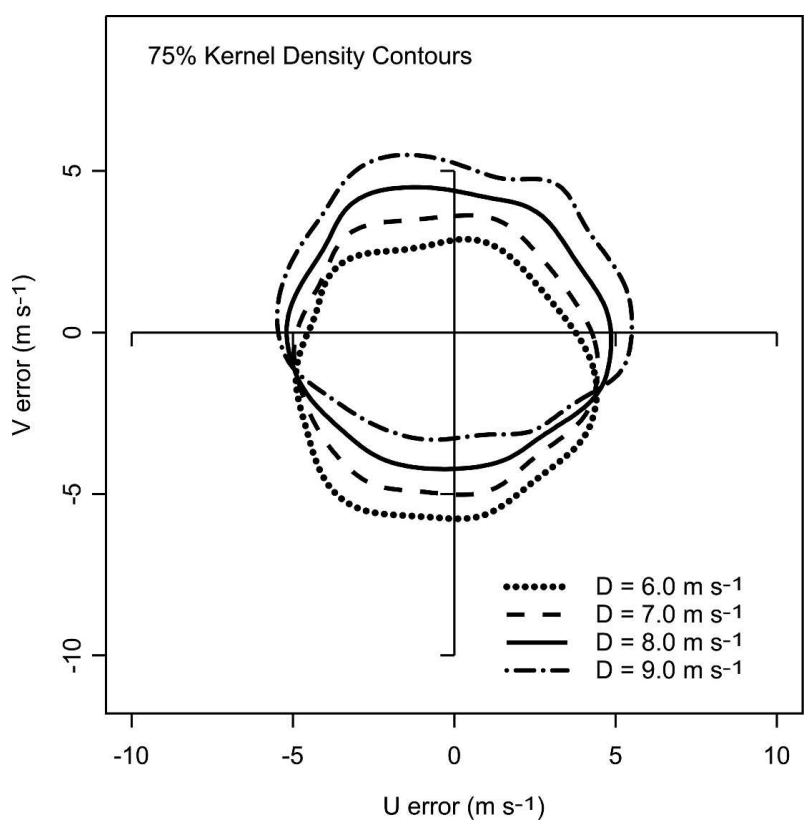

FIG. 6. KDE plot showing distribution of vector errors using different $D$ values from the $0-8 \mathrm{~km}$ mean wind (without pressure weighting) in the Bunkers scheme. Vertical wind shear layer is from $\mathrm{BL}$ to $5.5-6 \mathrm{~km}$. lated using a shallower layer, the 30R75 method resulted in an underestimate of both the rightward deviation in direction from the mean wind, and the speed of motion. For instance, it was found that when using a 0-6 km mean wind, the forecast errors were minimized using directional deviations ranging from $30^{\circ}$ to $40^{\circ}$ to the right of the mean wind, and speed deviations between $90 \%$ and $100 \%$ (Table 5). The difference between the optimum deviation angles associated with the $0-10 \mathrm{~km}$ mean wind and 0-6 km mean wind can be seen schematically in Fig. 9. The median $u$ component of the mean wind has a tendency to increase as the depth of the mean wind layer increases, which is to be expected owing to the typical increase of wind speed with height in supercell environments, of course.

Evidently, the minimum MDVE associated with the $0-10-\mathrm{km}$ mean wind $\left(4.1 \mathrm{~m} \mathrm{~s}^{-1}\right)$ was around $1 \mathrm{~m} \mathrm{~s}^{-1}$ less than the corresponding error associated with the $0-6$ $\mathrm{km}$ mean wind $\left(5.0 \mathrm{~m} \mathrm{~s}^{-1}\right)$. This result suggests that, despite the apparent differences in the mean deviant direction and speed, the method is most suitably applied to relatively deep mean wind layers. The use of pressure weighting to define the mean wind layer resulted in an overall decrease in the scheme's accuracy (not shown).

\section{d. The DJ93 scheme}

Following DJ93, the observed storm motions were stratified according to the magnitude of the $0-6 \mathrm{~km}$ mean wind speed. The observed directional deviation varied from $8^{\circ}$ left to $168^{\circ}$ right of the mean wind, and the speed deviation ranged from $17 \%-672 \%$ of the mean wind speed. This spread is significantly broader than what was shown in DJ93, in which the storm motions ranged from $2^{\circ}$ left to $42^{\circ}$ right of the mean wind direction, and $58 \%-158 \%$ of the mean wind speed. The large difference may be due to the difference in the number of cases between the current study and the original ( $N=394$ and $N=31$, respectively), and that only tornadic supercells were investigated in DJ93.

The current work supports the notion that the 
TABLE 3. MDVE and $(u, v)$ bias (italic) associated with various combinations of $D$ and bulk shear layer in the RB98 scheme.

\begin{tabular}{|c|c|c|c|c|c|c|}
\hline & \multicolumn{6}{|c|}{ Deviation from bulk shear layer } \\
\hline & & $6 \mathrm{~m} \mathrm{~s}^{-1}$ & $7 \mathrm{~m} \mathrm{~s}^{-1}$ & $7.5 \mathrm{~m} \mathrm{~s}^{-1}$ & $8.6 \mathrm{~m} \mathrm{~s}^{-1}$ & $10 \mathrm{~m} \mathrm{~s}^{-1}$ \\
\hline \multirow{6}{*}{ Bulk shear layer } & $\mathrm{BL}-3 \mathrm{~km}$ & $\begin{array}{c}5.9 \\
-4.1+1.9\end{array}$ & $\begin{array}{c}5.7 \\
-4.1+1.1\end{array}$ & $\begin{array}{c}5.6 \\
-4.1+0.6\end{array}$ & $\begin{array}{c}5.6 \\
-4.1-0.3\end{array}$ & $\begin{array}{c}6.0 \\
-4.1-1.4\end{array}$ \\
\hline & BL-4 km & $\begin{array}{c}4.4 \\
-2.6+1.5\end{array}$ & $\begin{array}{c}4.2 \\
-2.6+0.7\end{array}$ & $\begin{array}{c}4.3 \\
-2.7+0.2\end{array}$ & $\begin{array}{c}4.4 \\
-2.7-0.7\end{array}$ & $\begin{array}{c}5.1 \\
-2.7-1.9\end{array}$ \\
\hline & $\mathrm{BL}-5 \mathrm{~km}$ & $\begin{array}{c}3.7 \\
-1.2+1.3\end{array}$ & $\begin{array}{c}3.7 \\
-1.3+0.4\end{array}$ & $\begin{array}{c}3.7 \\
-1.3-0.0\end{array}$ & $\begin{array}{c}3.9 \\
-1.3-1.0\end{array}$ & $\begin{array}{c}4.6 \\
-1.4-2.1\end{array}$ \\
\hline & BL-6 km & $\begin{array}{c}3.7 \\
-0.1+1.3\end{array}$ & $\begin{array}{c}3.7 \\
+0.1+0.4\end{array}$ & $\begin{array}{c}3.9 \\
0.0-0.0\end{array}$ & $\begin{array}{l}4.0 \\
0.0-1.0\end{array}$ & $\begin{array}{c}4.7 \\
+1.1-2.0\end{array}$ \\
\hline & $\mathrm{BL}-7 \mathrm{~km}$ & $\begin{array}{c}4.6 \\
+1.2+1.5\end{array}$ & $\begin{array}{c}4.4 \\
+1.2+0.6\end{array}$ & $\begin{array}{c}4.4 \\
+1.1+0.2\end{array}$ & $\begin{array}{c}4.9 \\
+1.1-0.8\end{array}$ & $\begin{array}{c}5.6 \\
+1.1-2.0\end{array}$ \\
\hline & BL-8 km & $\begin{array}{c}5.5 \\
+2.4+1.5\end{array}$ & $\begin{array}{l}5.7 \\
+2.4+0.7\end{array}$ & $\begin{array}{c}5.7 \\
+2.4+0.2\end{array}$ & $\begin{array}{c}5.8 \\
+2.3-0.7\end{array}$ & $\begin{array}{c}6.5 \\
+2.3-1.9\end{array}$ \\
\hline
\end{tabular}

amount by which the storm motions deviate from the 0-6 km mean wind depends upon the magnitude of the mean wind speed. For weaker mean wind fields (i.e., $0-6 \mathrm{~km}$ mean wind $<15 \mathrm{~m} \mathrm{~s}^{-1}$ ) it was found that the storms deviated on average 40R105, whereas for stronger mean wind fields (i.e., 0-6 km mean wind $>15$ $\mathrm{m} \mathrm{s}^{-1}$ ), the mean deviant motion was closer to the original suggestion at 25R85 (see Fig. 10 for a qualitative illustration of this difference).

Our results differ somewhat from those presented in DJ93, however. We found a tendency for the 0-6 km mean wind to underestimate the speed of the storm motion when the magnitude of the mean wind is less

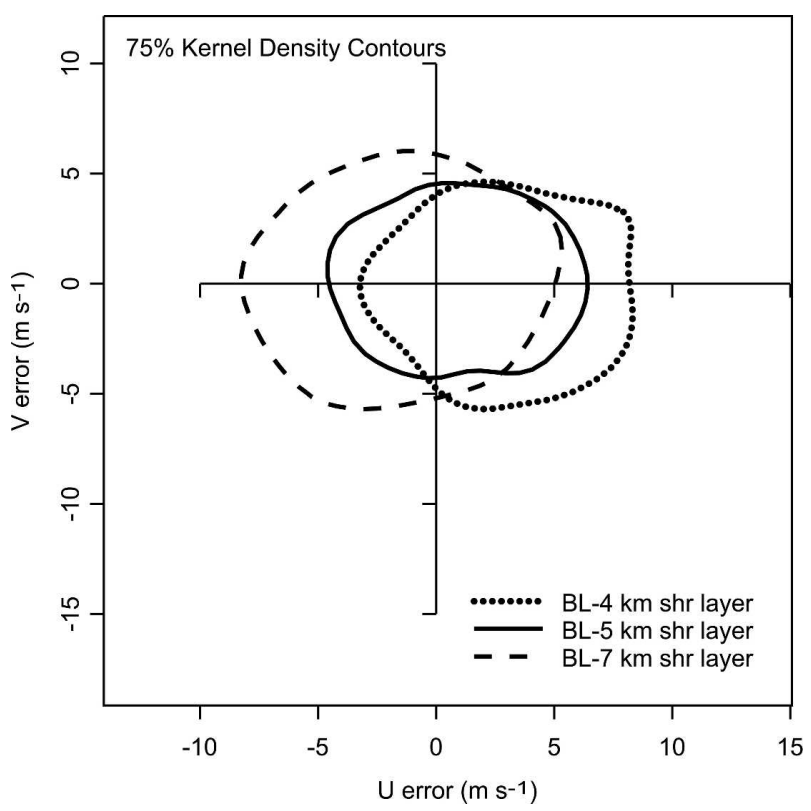

FIG. 7. KDE plot showing the distribution of forecast vector errors using the $0-4,0-5$, and $0-7 \mathrm{~km}$ bulk shear layers in the RB98 scheme; $D=8.6 \mathrm{~m} \mathrm{~s}^{-1}$. than $15 \mathrm{~m} \mathrm{~s}^{-1}$. Furthermore, the fractional proportion of the mean wind used to forecast the storm motion was shown to increase as the mean wind field decreased. DJ93 found the opposite result.

\section{e. The C80 scheme}

Despite being the most complex of all the forecast algorithms, the $\mathrm{C} 80$ scheme produced the largest errors (Table 6). The $u$ component of the estimated storm motion was regulated largely by the depth of the vertically integrated, horizontal wind field. On the other hand, the $v$ component was found to be relatively in-

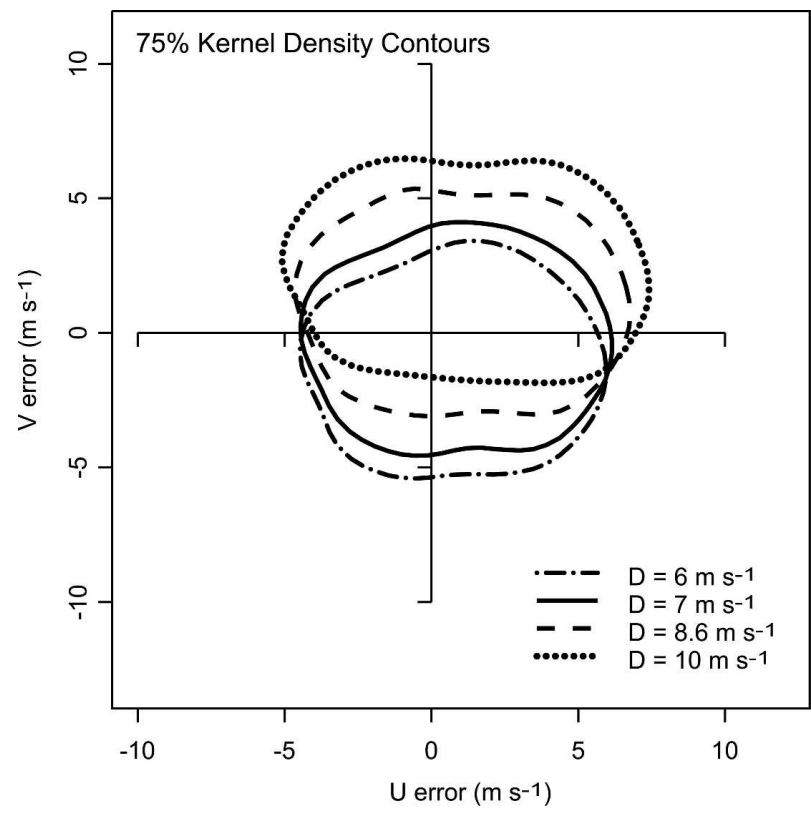

FIG. 8. KDE plot showing the distribution of forecast vector errors associated with varying the value of $D$ in the RB98 scheme. Vertical wind shear layer is held constant at BL-5 km. 
TABLE 4. MDVEs $\left(\mathrm{m} \mathrm{s}^{-1}\right)$ for the variations on $30 \mathrm{R} 75$ using the $0-10-\mathrm{km}$ mean wind layer (without pressure weighting).

\begin{tabular}{|c|c|c|c|c|c|c|}
\hline & \multicolumn{6}{|c|}{ Degrees to the right of the mean wind } \\
\hline & & $10^{\circ}$ & $20^{\circ}$ & $30^{\circ}$ & $40^{\circ}$ & $50^{\circ}$ \\
\hline \multirow{7}{*}{$\begin{array}{l}\text { Fractional speed of } \\
\text { mean wind }\end{array}$} & $60 \%$ & 6.0 & 5.1 & 4.6 & 4.9 & 5.6 \\
\hline & $65 \%$ & 5.8 & 4.7 & 4.3 & 4.6 & 5.4 \\
\hline & $70 \%$ & 5.6 & 4.6 & 4.1 & 4.3 & 5.3 \\
\hline & $75 \%$ & 5.5 & 4.6 & 4.1 & 4.3 & 5.3 \\
\hline & $80 \%$ & 5.6 & 4.7 & 4.2 & 4.4 & 5.5 \\
\hline & $85 \%$ & 5.9 & 4.7 & 4.3 & 4.6 & 5.7 \\
\hline & $90 \%$ & 6.2 & 4.9 & 4.4 & 4.9 & 6.0 \\
\hline
\end{tabular}

sensitive to this parameter. The minimum forecast error was found by using the integrated SFC $-350 \mathrm{hPa}$ mass flux layer. This result extends the original C80 scheme, in which only the SFC-450-hPa layer was considered. In addition, the forecast errors obtained for the new dataset were substantially larger (about $5 \mathrm{~m} \mathrm{~s}^{-1}$ ) than those presented in the original paper.

\section{f. The offset method}

The dispersion of forecast errors associated with the offset method for each mean wind layer (without pressure weighting) was shown to be relatively insensitive to changes in the mean wind layer, as it was varied from 0-6 to $0-12 \mathrm{~km}$ (Fig. 11). The minimum MDVE was obtained using the $0-8-\mathrm{km}$ layer, with an associated offset vector of $(u=-0.7, v=-7.1) \mathrm{m} \mathrm{s}^{-1}$. This optimum deviation vector magnitude is consistent with those used in both the Bunkers and the RB98 schemes. The latter schemes impose an additional shear-relative directional constraint $\left(90^{\circ}\right.$ and to the right of the mean wind or shear vector) on the offset vector, whereas this simple method has no such constraint. Further, the $v$ component of the offset vector for each layer remained relatively constant, at around $7 \mathrm{~m} \mathrm{~s}^{-1}$, whereas the $u$ component varied from +1.8 to $-3.9 \mathrm{~m} \mathrm{~s}^{-1}$. The minimum in error dispersion associated with the $0-8 \mathrm{~km}$

TABLE 5. MDVEs $\left(\mathrm{m} \mathrm{s}^{-1}\right)$ for the variations on $30 \mathrm{R} 75$ using the 0-6-km mean wind layer (without pressure weighting).

\begin{tabular}{crrrrrrr}
\hline \hline & \multicolumn{7}{c}{ Degrees to the right of the mean wind } \\
\cline { 2 - 8 } & & $10^{\circ}$ & $20^{\circ}$ & $30^{\circ}$ & $40^{\circ}$ & $50^{\circ}$ \\
\hline \multirow{3}{*}{ Fractional speed of } & $70 \%$ & 7.0 & 6.2 & 5.9 & 5.7 & 6.0 \\
mean wind & $75 \%$ & 6.9 & 5.9 & 5.5 & 5.5 & 5.8 \\
& $85 \%$ & 6.9 & 5.8 & 5.2 & 5.3 & 5.8 \\
& $90 \%$ & 6.9 & 5.6 & 5.1 & 5.2 & 5.7 \\
& $95 \%$ & 7.0 & 5.8 & 5.0 & 5.2 & 5.6 \\
& $100 \%$ & 7.1 & 6.0 & 5.2 & 5.3 & 5.6 \\
\hline
\end{tabular}

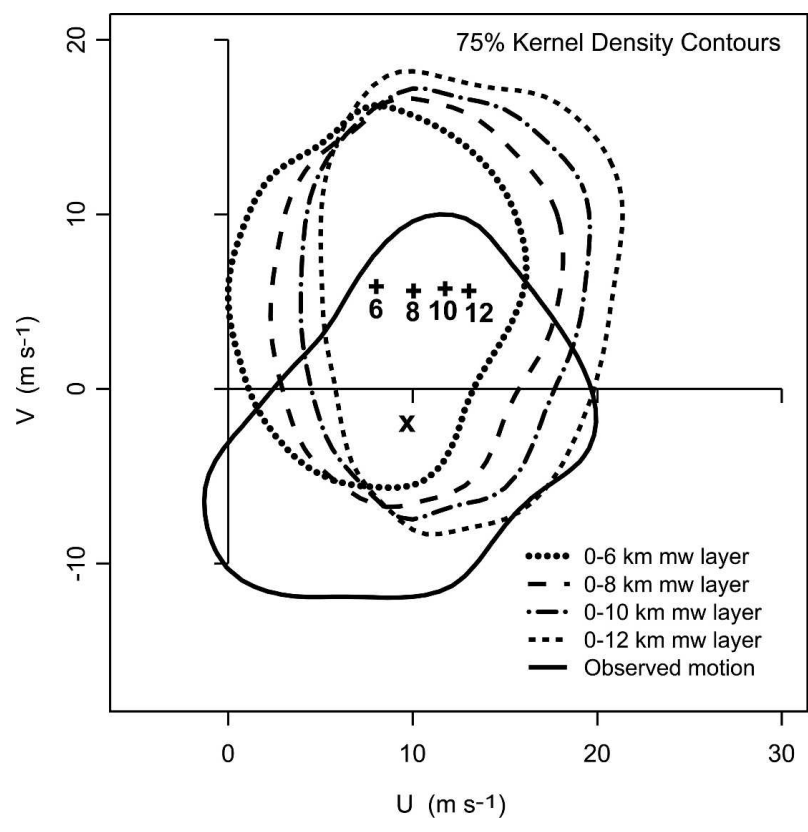

FIG. 9. KDE plot showing the observed storm motions in the new dataset relative to the mean wind of various layers. The median of each mean wind vector distribution is marked by a plus sign. The median $(u, v)$ of the observed storm motion distribution is marked by $\times$.

layer suggests that this may be the most representative layer, on the average, to estimate the advection component of supercell motion, but the differences among the layers are minor.

\section{g. A comparative analysis of all the storm motion schemes}

In terms of general forecast performance, the revised Bunkers scheme $\left(\mathbf{V}_{\text {mean }}\right.$ layer $=0-8 \mathrm{~km}, \partial \mathbf{V} / \partial z$ layer $=$ BL to $5.5-6 \mathrm{~km}, D=7.5 \mathrm{~m} \mathrm{~s}^{-1}$ ) results in the minimum forecast error $\left(\mathrm{MDVE}=2.9 \mathrm{~m} \mathrm{~s}^{-1}\right.$ ), and is more accurate than the other schemes for 131 out of 385 cases in the new dataset (Table 7). The revised RB98 scheme $\left(\partial \mathbf{V} / \partial z\right.$ layer $\left.=\mathrm{BL}-5 \mathrm{~km}, D=7.5 \mathrm{~m} \mathrm{~s}^{-1}\right)$ has the second lowest forecast error $\left(\mathrm{MDVE}=3.7 \mathrm{~m} \mathrm{~s}^{-1}\right)$, whereas the offset method (MDVE $=4.2 \mathrm{~m} \mathrm{~s}^{-1}$ ) and revised M76 scheme (MDVE $=4.1 \mathrm{~m} \mathrm{~s}^{-1}$ ) perform comparatively well. A relatively strong correlation $(r=0.68)$ of the forecast errors in the Bunkers and RB98 schemes indicates that they are somewhat similar. The C 80 scheme performed demonstrably worse than the other schemes, as evidenced by the large forecast errors associated with it $\left(\mathrm{MDVE}=6.2 \mathrm{~m} \mathrm{~s}^{-1}\right)$.

If we consider the offset method to be a baseline for comparison rather than a proper forecasting scheme, then we can use the foregoing results to assess the rela- 


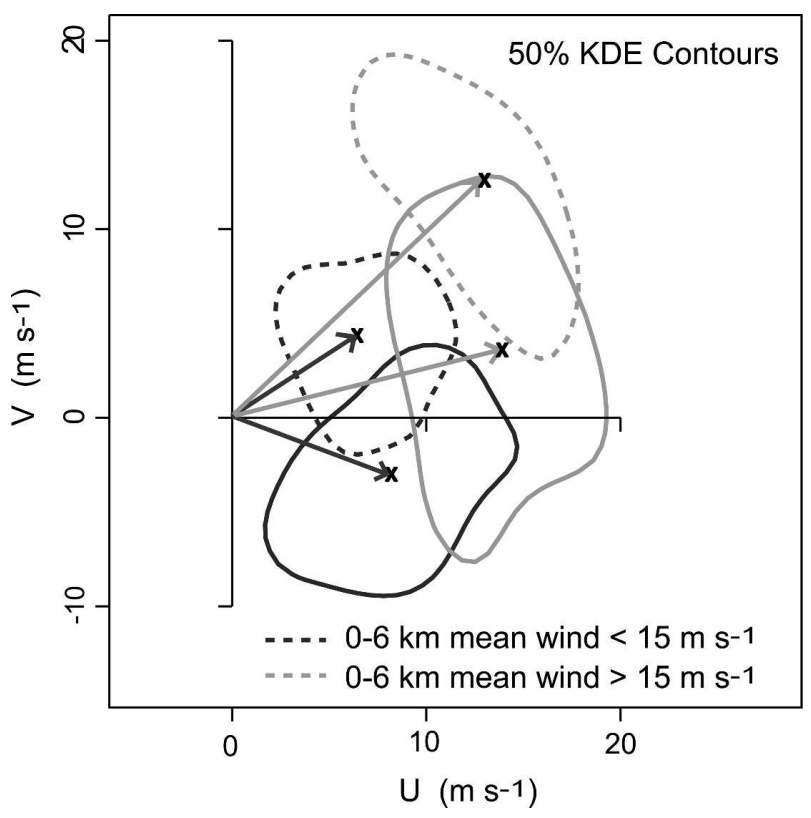

FIG. 10. KDE plot showing the observed storm motions partitioned by the $0-6-\mathrm{km}$ mean wind speed, as in the DJ93 scheme. Dashed lines show the observed 0-6 km mean wind vector distributions for speeds less than (dark gray) and greater than (light gray) $15 \mathrm{~m} \mathrm{~s}^{-1}$. The solid lines show the corresponding observed storm motion distributions. The $\times$ symbols denote the $(u, v)$ median of each distribution.

tive skill of the schemes. Given that skill is based on the difference in accuracy between a given scheme and the baseline, a general formula for the skill score is

$$
\mathrm{SS}_{\mathrm{ref}}=\frac{A-A_{\text {ref }}}{A_{\text {perf }}-A_{\text {ref }}} \times 100 \%,
$$

where $A$ is a particular measure of accuracy, $A_{\text {ref }}$ is the same measure of accuracy for the reference forecasts, and $A_{\text {perf }}$ is accuracy measure achieved by a perfect forecast (Wilks 1995). When using the MDVE as the accuracy measure, the skill scores for the four schemes (Table 8), with the exception of C80, reveal an improvement over the reference forecast provided by the offset method. The revised Bunkers scheme resulted in the greatest improvement, with a skill score of $31 \%$.

Although the Bunkers and RB98 schemes provide the best storm motion estimates, on the average

TABLE 6. Summary statistics describing the vector errors for each "optimized" scheme.

\begin{tabular}{lrccrr}
\hline \hline Statistic & C80 & Bunkers & RB98 & M76 & Offset \\
\hline Mean & 7.2 & 3.4 & 4.0 & 4.5 & 4.6 \\
Median & 6.2 & 2.9 & 3.7 & 4.1 & 4.2 \\
Maximum & 25.7 & 12.4 & 16.0 & 14.0 & 15.6 \\
\hline
\end{tabular}

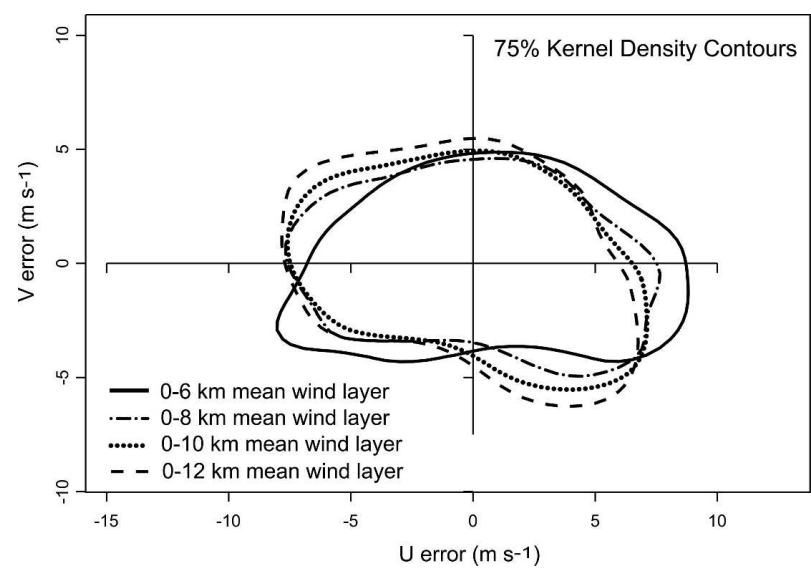

FIG. 11. KDE plot showing the distribution of forecast vector errors associated with the empirically derived offset vectors for four different wind layers.

(Figs. 12 and 13), for any given day, it is difficult to know which scheme to use (Table 8). Additional information obtained from the sounding did not reduce this uncertainty. Indeed, all the forecast schemes are capable of producing both very small forecast errors (less than $0.3 \mathrm{~m} \mathrm{~s}^{-1}$ ) and very large forecast errors (greater than $12 \mathrm{~m} \mathrm{~s}^{-1}$ ), as shown in Table 6 . The difficulty lies in determining which environments are conducive to these extremes. We were unable to identify any characteristic of the environment that would be useful in doing so.

The distribution of the absolute vector errors for each forecast scheme is positively skewed, owing to the large positive outliers. This results in the MDVE, or the 50th percentile of the errors, being less than the MVE. This was expected, since in general, data that are physically constrained to lie above a certain minimum value are often positively skewed (Wilks 1995).

The Bunkers scheme is statistically superior to its nearest competitor, RB98, as well as the other schemes, based on the Wilcoxon signed-rank test $\left(\mathrm{H}_{\mathrm{A}}: M_{d} \neq 0\right.$, $\alpha=0.01, Z=-6.196, p<0.00001)$. The superiority of the Bunkers and RB98 schemes is greatest for hodographs in which the wind profile deviated markedly

TABLE 7. The relative accuracy of the four forecast schemes and the offset method when compared head to head, using 385 cases from the new dataset. First designates the minimum vector error per event, and fifth designates the maximum vector error.

\begin{tabular}{lccccr}
\hline \hline Scheme & First & Second & Third & Fourth & Fifth \\
\hline Bunkers & 131 & 119 & 82 & 42 & 9 \\
RB98 & 98 & 85 & 72 & 75 & 55 \\
Offset & 64 & 72 & 94 & 88 & 67 \\
M76 & 68 & 70 & 93 & 115 & 39 \\
C80 & 24 & 39 & 44 & 63 & 215 \\
\hline
\end{tabular}


TABLE 8. Skill scores (\%) for the four forecast schemes, using the offset method as a reference.

\begin{tabular}{ccccc}
\hline \hline & C80 & M76 & RB98 & Bunkers \\
\hline SS (\%) & -47.6 & 2.4 & 11.9 & 31.0 \\
\hline
\end{tabular}

from the mean (recall Fig. 1). For a subset of 41 "atypical" hodographs, defined arbitrarily as those with either a $0-6-\mathrm{km}$ mean wind speed of less than $5 \mathrm{~m} \mathrm{~s}^{-1}$, or a $0-10-\mathrm{km} v$ component of less than $-10 \mathrm{~m} \mathrm{~s}^{-1}$, the Bunkers and RB98 schemes result in MDVEs of 2.9 and 3.1 $\mathrm{m} \mathrm{s}^{-1}$, respectively, whereas the other schemes perform considerably worse (Table 9). Furthermore, the optimum forecast errors (i.e., the lowest MVE/MDVE resulting from some optimum combination of parameters) in both the Bunkers and RB98 schemes are less for the atypical cases than the typical cases (Table 9).

\section{h. Some general observations concerning the new dataset.}

The observed storm motions varied in direction from north-northeasterly to southwesterly; however, most were clustered in the first and fourth quadrants of the hodograph. Interestingly, a small subset of supercells moved toward the southwest. It was found that such atypical storm motions were generally accompanied by deep northerly or northwesterly flow. However, the average proximity hodograph was characterized by

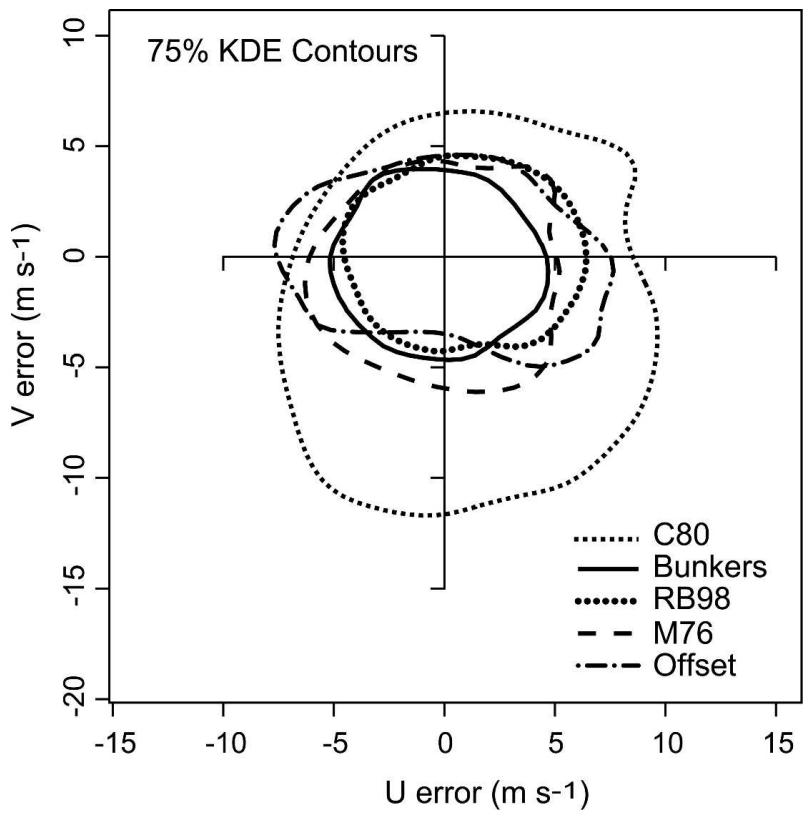

FIG. 12. KDE plot showing the distribution of forecast vector errors for each "optimum" scheme. The offset method is shown for comparison.

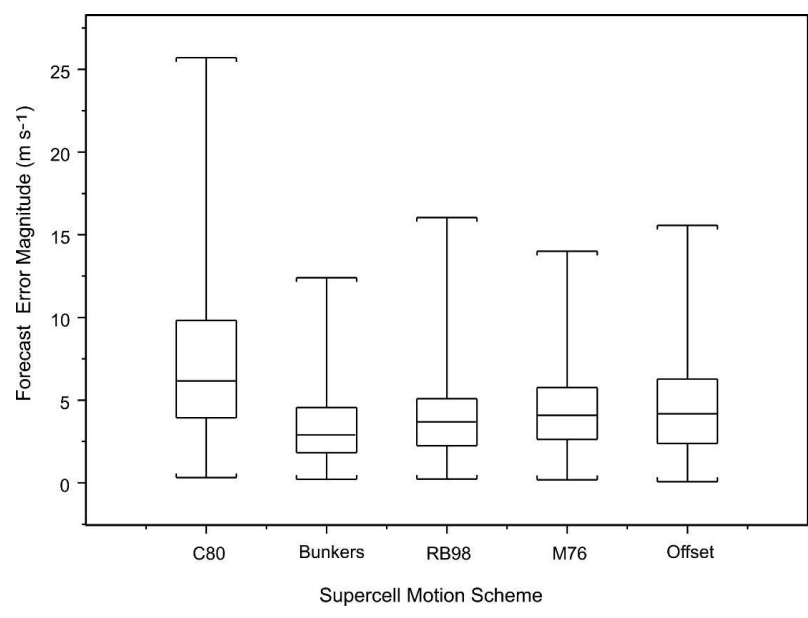

FIG. 13. Box-and-whisker plot showing distribution of forecast error magnitudes for each optimum scheme, as well as the offset method. Medians are marked by the horizontal bar in each box.

a southeasterly wind at the surface, a south-southwesterly wind at $850 \mathrm{hPa}$, and a general west-southwesterly flow aloft (Fig. 1). This wind profile closely resembles the proximity hodographs shown in Markowski et al. (2003) as well as many other examples in the literature. Although most of the supercells deviated to the right of the mean wind regardless of which mean wind layer was used, there were six cases in which the supercells deviated to the right of the $0-6 \mathrm{~km}$ mean wind, but to the left of the $0-8,0-10$, and $0-12 \mathrm{~km}$ mean winds. This is an interesting result, since it raises questions about the definition of a "right moving" supercell, discussed further in the next section.

It has been shown that the Galilean-invariant, shearrelative schemes can be superior to the other schemes for atypical hodographs, or for those cases in which the average tropospheric flow is north-northwesterly. As Bunkers et al. (2000) pointed out, the relative accuracy of the M76 scheme in the past is apparently attributable to the observation that the average supercell proximity wind profile tends to reside primarily in the top-right quadrant of the hodograph. Indeed, the current study indicates that for such hodographs, the error difference between the Bunkers and M76 scheme is less. However, when the wind profile (and hence the vertical shear vector) is confined to the lower quadrants of the hodograph, or when the mean wind is relatively weak, the Bunkers and RB98 schemes perform substantially better than those schemes based on the mean wind alone (Table 9).

The angle between the observed storm motion and the $0-6 \mathrm{~km}$ mean wind vector was found to increase as the magnitude of the $0-6 \mathrm{~km}$ mean wind decreased (Fig. 14a). The average magnitude of the deviation vector 
TABLE 9. MVE, MDVE, and $(u, v)$ bias for each optimum scheme and the offset method, using 353 typical hodographs and 41 atypical hodographs.

\begin{tabular}{lccccc}
\hline \hline & & Typical hodographs $(N=353)$ & & \\
& C80 & M76 & RB98 & Bunkers & Offset \\
\hline MVE $\left(\mathrm{m} \mathrm{s}^{-1}\right)$ & 7.2 & 4.4 & 4.1 & 3.5 & 4.5 \\
Bias $(u, v)$ & $-2.2,+1.9$ & $-0.3,+0.4$ & $-1.3,0.0$ & $+0.1,+0.6$ & $+0.6,-0.1$ \\
MDVE $\left(\mathrm{m} \mathrm{s}^{-1}\right)$ & 5.9 & 3.9 & 3.8 & 2.9 & 4.0 \\
Bias $(u, v)$ & $-1.4,+2.4$ & $-0.2,+0.4$ & $-1.1,-0.1$ & $+0.2,+0.7$ & $+0.2,-0.1$ \\
& & Atypical hodographs $(N=41)$ & Bunkers & Offset \\
\hline MVE $\left(\mathrm{m} \mathrm{s}^{-1}\right)$ & C80 & M76 & RB98 & 3.1 & 5.3 \\
Bias $(u, v)$ & 6.8 & 4.9 & 3.4 & $-0.7,0.0$ & $-1.8,+2.0$ \\
MDVE $\left(\mathrm{m} \mathrm{s}^{-1}\right)$ & $+1.6,+4.4$ & $+0.2,+3.0$ & $-1.5,-0.2$ & 2.9 & 4.8 \\
$\operatorname{Bias}(u, v)$ & 6.6 & 5.2 & 3.1 & $-0.5,-0.3$ & $-3.1,+1.7$ \\
\hline
\end{tabular}

(absolute vector difference between the observed motion and the mean wind) was about $9 \mathrm{~m} \mathrm{~s}^{-1}$, and was independent of the 0-6 km mean wind speed (Fig. 14b). Hence, there was little predictive relationship between the length of the deviation vector and the mean wind speed alone.
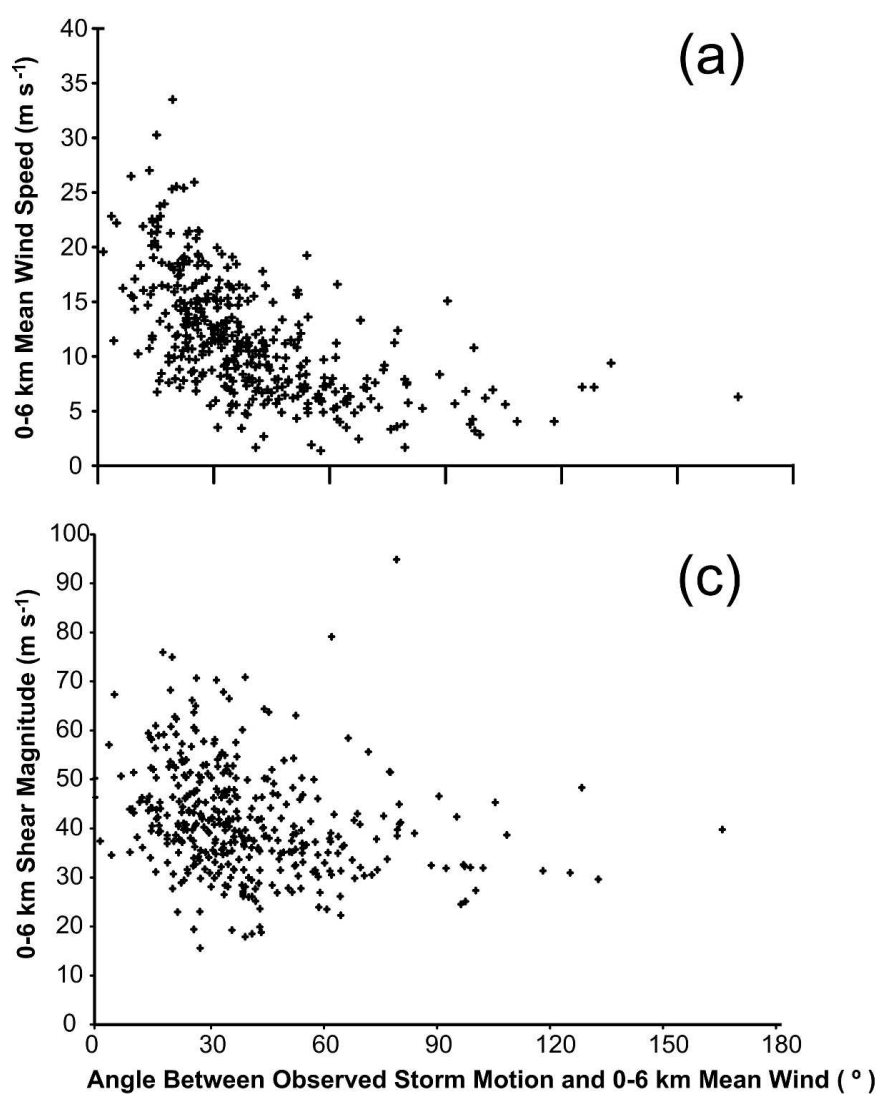

A similar absence of a predictive relationship was found between the $0-6 \mathrm{~km}$ total shear magnitude (the length of the shear vector) and the observed storm motion deviation from the $0-6 \mathrm{~km}$ mean wind vector (Figs. $14 \mathrm{c}, \mathrm{d})$. The $0-6 \mathrm{~km}$ total shear magnitude ranged from $2.5 \times 10^{-3} \mathrm{~s}^{-1}$ to $1.58 \times 10^{-2} \mathrm{~s}^{-1}$ (or 15 to $95 \mathrm{~m} \mathrm{~s}^{-1}$,
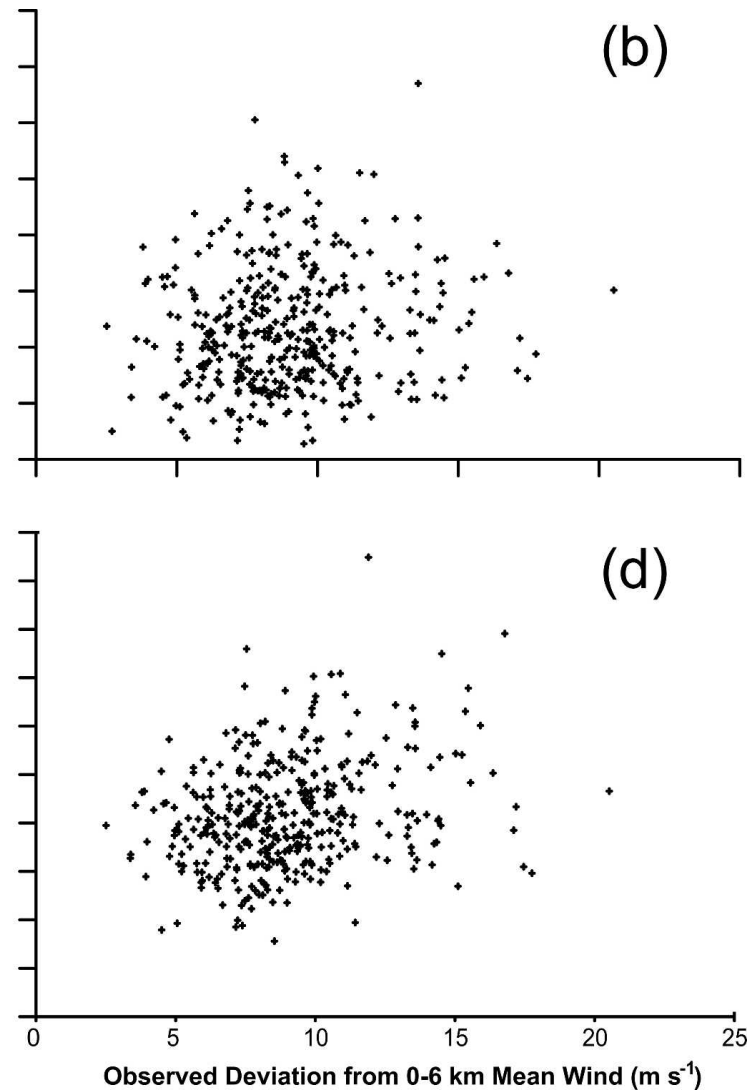

FIG. 14. Scatterplots showing (a) the angular deviation of the observed supercell motion from the $0-6 \mathrm{~km}$ mean wind vs the 0-6 km mean wind speed, (b) the magnitude of deviation of the observed supercell motion from the 0-6 km mean wind vs the 0-6 km mean wind speed, (c) the angular deviation of the observed supercell motion from the 0-6 km mean wind vs the 0-6 km total shear magnitude, and (d) the magnitude of deviation of the observed supercell motion from the 0-6 km mean wind vs the 0-6 km total shear magnitude. 
over the 6-km depth), with a mean of $7 \times 10^{-3} \mathrm{~s}^{-1}(42$ $\mathrm{m} \mathrm{s}^{-1}$ ). There was a slight tendency for the observed deviation magnitude to increase as the shear magnitude increased $(r=0.26)$.

Of some interest is the modest positive correlation between the $0-6 \mathrm{~km}$ mean wind speed and the $0-6-\mathrm{km}$ shear magnitude $(r=0.49)$. Evans and Doswell (2001) demonstrated a similar relationship in their examination of derecho environments. Since the mean wind speed and the shear were not uncorrelated, it is uncertain to what extent the observed deviation is affected by the shear magnitude alone.

\section{Issues related to the prediction of storm motion}

It has been found that the majority of the rightmoving supercells presented herein are associated with strong clockwise turning of the shear vector between the surface and $700 \mathrm{hPa}$. Indeed, it has been suggested (e.g., Rotunno and Klemp 1982) that this clockwise turning of the shear vector with height promotes the development of a cyclonic right-moving storm. This theory is the underlying premise behind the deviation term in the Bunkers scheme, as seen in Eq. (1).

Despite the high relative accuracy of the Bunkers scheme on the average, there were times when it produced large errors $\left(>10 \mathrm{~m} \mathrm{~s}^{-1}\right)$. These errors suggest that supercell storm motion is determined by more than just the mean wind and the vertical wind shear. In fact, we found that most of the large errors in the Bunkers scheme were associated with either high-precipitation (HP) supercells, or supercells that eventually evolved into bow echoes. Likewise, RB98 found that, based on climatological data, HP supercells have a tendency to deviate more to the right than their predicted motion, and that such deviation does not appear to be related to the vertical wind shear in the lowest half of the troposphere. Other studies have shown that HP supercells tend to develop and move along preexisting thermal boundaries, including old outflow boundaries and stationary fronts (Maddox et al. 1980; Zehr and Purdom 1982; Moller et al. 1990; Guyer 2002; Sills et al. 2004), which can have orientations promoting movement by propagation that would be quite different from those based on the hodograph alone. This may explain some of the large forecast errors in the Bunkers scheme.

Furthermore, it has been shown that the "optimum" values of the parameters in all the schemes (based on their average behavior) do not always yield an accurate forecast. Consequently, selecting the most suitable mean wind and/or vertical wind shear layer to be used in these schemes is a nontrivial issue. Bunkers et al.
(2000) suggested that a mean wind layer less than 0-6 km may be more suitable for shallow or low-topped supercells. However, indications from the current study do not seem to support this hypothesis.

This issue was explored further by allowing the depth of the mean wind layer to be determined by information other than the hodograph (i.e., the LCL, LFC, and the EL) rather than arbitrary fixed heights. The possible advantages of making the mean wind a function of one or more of the above parameters have been discussed in previous studies (Weaver 1979; Zehr and Purdom 1982; Bunkers et al. 2000), though never tested. We found, instead, that that forecast errors increased substantially when using the LCL-EL or LFC-EL to calculate the mean wind, rather than the SFC-EL. Despite the apparent advantages of using a shear-relative forecast scheme with a fixed deviation vector, the observed storm motions revealed only a weak linear relationship between the deviation from the $0-6 \mathrm{~km}$ mean wind and the magnitude of the $0-6 \mathrm{~km}$ vertical wind shear. This suggests that the vertical wind shear is only one of several factors contributing to the propagation component of supercell motion. Indeed, Weaver (1979) suggested that supercell motion may be influenced by preexisting boundary layer convergence zones, as well as outflow boundaries produced by the storms themselves. Supercells have also been observed to move across these low-level boundaries (Maddox et al. 1980) rather than along them, so this remains an unresolved issue.

Recall that there were several cases in which the observed storm motion was to the right of the $0-6 \mathrm{~km}$ mean wind, but to the left of the $0-8$ to $0-12 \mathrm{~km}$ mean winds. This result raises some concerns about the definition of a right-moving supercell. If a supercell is classified as right moving, it appears it might be necessary to specify with respect to which mean wind layer. For instance, Browning (1964) asserts that the supercell travels to the right of winds in the "middle troposphere," with no specifics provided. In a case study of splitting thunderstorms over Iowa, Achtemeier (1969) posited that the right member of the split veered sharply to the right of the mean wind, but did not specify the mean wind layer at all. Maddox (1976) defined the mean wind to be the mean vector of the observed winds between the surface and $200 \mathrm{hPa}$, whereas Davies and Johns (1993) employed the 0-6 km mean wind in their calculations of deviant storm motion.

The aforementioned studies reveal considerable inconsistency and ambiguity when attempting to define the "mean wind." Our study has shown that the direction, as well as the magnitude, of the mean wind is strongly dependent on the layer over which the mean is 
calculated. There seems to be no consensus definition of the environmental mean wind layer for a rightmoving supercell, although the use of the $0-6 \mathrm{~km}$ layer is widespread.

\section{Summary and conclusions}

Four supercell motion forecast schemes were explored with respect to their arbitrary hodograph analysis parameters, and compared with one another. The offset method (not a forecast scheme) was developed to serve as a baseline method by which the relative skill of the forecast schemes could be compared.

The Bunkers scheme proved to be slightly superior to the other schemes in terms of both the MVE and MDVE, and exhibits the greatest skill relative to the offset method. However, it was found necessary to modify the mean wind parameters specified in the original Bunkers scheme in order to find the minimum MDVE (2.9 $\mathrm{m} \mathrm{s}^{-1}$ ). The use of the LCL, LFC, and EL to define the mean wind layer led to larger forecast errors than when using arbitrary fixed heights, such as $0-8 \mathrm{~km}$. It was found that the inclusion of the winds in the subcloud layer was necessary to obtain the minimum forecast errors for the Bunkers scheme. Based on the results presented herein, we suggest that the original Bunkers scheme can be improved by changing the mean wind layer from $0-6$ to $0-8 \mathrm{~km}$.

The revised RB98 scheme resulted in the second lowest forecast errors and second highest skill, and was found to give results similar to the Bunkers scheme. The apparent success of these forecast schemes may be due to their Galilean-invariant, shear-relative properties. This is particularly evident for supercells within wind profiles that deviate significantly from the average supercell hodograph. Nevertheless, there are situations in which both the Bunkers and RB98 schemes yield considerably large forecast errors. It was found that these large errors are often associated with HP supercells, or supercells that evolve into bow-echo structures.

It has been shown that when applying the M76-type schemes, it is advantageous to use a deep mean wind layer (i.e., 0-10 km or deeper). Furthermore, the M76 scheme revealed a propensity for the angle between the mean wind vector and the observed storm motion to increase as the magnitude of the mean wind decreased. The offset method produced its best motion estimates using the same wind layer and deviation magnitude as used in the Bunkers scheme.

Finally, the C80 scheme performed demonstrably worse than the other forecast schemes when compared head to head, and this is highlighted by its relatively large MDVE and negative skill level relative to the offset method. Thus, we do not recommend that this scheme be used in operational forecasting.

The current work has demonstrated that forecasting the motion of supercell storms is a complex issue. Thus, even the most successful schemes should be used with caution; the accuracy obtained over an ensemble of cases may not be representative for a particular case. Furthermore, the schemes are based on the assumption that the proximity hodograph is an appropriate representation of the actual environment in which the storm forms. Indeed, trying to define what constitutes the most suitable "proximity" sounding can be problematic. It is suggested that the influence of features not incorporated in hodograph-based schemes, such as outflow boundaries, warm fronts, and sea breezes, may account for some degree of the forecast errors associated with the forecast schemes investigated herein. This is beyond the scope of the current work, however, and constitutes work that remains to be done.

Acknowledgments. Publication of this manuscript was supported by National Science Foundation Grant ATM-0350539. The Cooperative Institute for Mesoscale Meteorological Studies (CIMMS) is acknowledged for financial support of the lead author of this study. We wish to thank Prof. Peter Lamb (CIMMS) for his personal encouragement. We also acknowledge Matthew Bunkers for willingly sharing his dataset, and for constructive comments on the manuscripts. We are grateful to Mr. John Hart (SPC) for his technical assistance with the code, as well as Dr. Harold Brooks (NSSL) for his insight and many beneficial suggestions. Professors Mike Richman (OU), Evgeni Fedorovich (OU), and Lance Leslie (OU) also made many contributions as members of the lead author's M.S. thesis advisory committee (which also included Dr. Brooks). Finally, we wish to thank the three anonymous reviewers for offering a number of beneficial suggestions.

\section{REFERENCES}

Achtemeier, G. L., 1969: Some observations of splitting thunderstorms over Iowa on August 25-26, 1965. Preprints, Sixth Conf. on Severe Local Storms, Chicago, IL, Amer. Meteor. Soc., $89-94$.

Beebe, R. G., 1958: An instability line development as observed by the tornado research airplane. J. Meteor., 15, 278-282.

Bowman, A. W., and A. Azzalini, 1997: Applied Smoothing Techniques for Data Analysis: The Kernel Approach with S-Plus Illustrations. Oxford University Press, 193 pp.

Brooks, H. E., and C. A. Doswell III, 1996: A comparison of measures-oriented and distributions-oriented approaches to forecast verification. Wea. Forecasting, 11, 288-303.

,$--\ldots$, and J. Cooper, 1994: On the environments of tornadic and nontornadic mesocyclones. Wea. Forecasting, 9, 606-618. Brown, R. A., 1993: A compositing approach for preserving sig- 
nificant features in atmospheric profiles. Mon. Wea. Rev., 121, 874-880.

Browning, K. A., 1964: Airflow and precipitation trajectories within severe local storms which travel to the right of the winds. J. Atmos. Sci., 21, 634-639.

, 1965a: The evolution of tornadic storms. J. Atmos. Sci., 22, 664-668.

_ 1965 b: Some inferences about the updraft within a severe local storm. J. Atmos. Sci., 22, 669-677.

Bunkers, M. J., B. A. Klimowski, J. W. Zeitler, R. L. Thompson, and M. L. Weisman, 2000: Predicting supercell motion using a new hodograph technique. Wea. Forecasting, 15, 61-79.

Colquhoun, J. R., 1980: A method of estimating the velocity of a severe thunderstorm using the vertical wind profile in the storm's environment. Preprints, Eighth Conf. on Weather Forecasting and Analysis, Denver, CO, Amer. Meteor. Soc., 316-323.

Darkow, G. L., 1969: An analysis of over sixty tornado proximity soundings. Preprints, Sixth Conf. on Severe Local Storms, Chicago, IL, Amer. Meteor. Soc., 218-221.

Davies, J. M., 1998: On supercell motion in weaker wind environments. Preprints, 19th Conf. on Severe Local Storms, Minneapolis, MN, Amer. Meteor. Soc., 685-688.

— , and R. H. Johns, 1993: Some wind and instability parameters associated with strong and violent tornadoes. Part I: Wind shear and helicity. The Tornado: Its Structure, Dynamics, Prediction, and Hazards, Geophys. Monogr., No. 79, Amer. Geophys. Union, 573-582.

Davies-Jones, R. P., 1984: Streamwise vorticity: The origin of updraft rotation in supercell storms. J. Atmos. Sci., 41, 29913006.

desJardins, M. L., K. F. Brill, and S. S. Schotz, 1991: GEMPAK 5. Part I-GEMPAK 5 programmer's guide. National Aeronautics and Space Administration, 176 pp. [Available from Scientific and Technical Information Division, Goddard Space Flight Center, Greenbelt, MD 20771.]

Doswell, C. A., III, and D. W. Burgess, 1993: Tornadoes and tornadic storms: A review of conceptual models. The Tornado: Its Structure, Dynamics, Prediction, and Hazards, Geophys. Monogr., No. 79, Amer. Geophys. Union, 161-182.

Droegemeier, K. K., S. M. Lazarus, and R. Davies-Jones, 1993: The influence of helicity on numerically simulated convective storms. Mon. Wea. Rev., 121, 2005-2029.

Evans, J. S., and C. A. Doswell III, 2001: Examination of derecho environments using proximity soundings. Wea. Forecasting, 16, 329-342.

Fankhauser, J. C., 1971: Thunderstorm environment interactions determined from aircraft and radar observations. Mon. Wea. Rev., 99, 171-192.

Guyer, J. L., 2002: A case of supercell intensification along a preexisting boundary-Clay County Nebraska tornado of 22 September 2001. Preprints, 21st Conf. on Severe Local Storms, San Antonio, TX, Amer. Meteor. Soc., 579-581.

Hart, J. A., and W. Korotky, 1991: The SHARP workstation v1.30 users guide. NOAA/National Weather Service, $30 \mathrm{pp}$.

Maddox, R. A., 1976: An evaluation of tornado proximity wind and stability data. Mon. Wea. Rev., 104, 133-142.

— , L. R. Hoxit, and C. F. Chappell, 1980: A study of tornadic thunderstorm interactions with thermal boundaries. Mon. Wea. Rev., 108, 322-336.

Markowski, P. M., and Y. P. Richardson, 2004: Multiple-Doppler radar observations of vertical wind profile heterogeneity in convective boundary layers. Preprints, $22 d$ Conf. on Severe Local Storms, Hyannis, MA, Amer. Meteor. Soc., CD-ROM, P13.1.

- J. M. Straka, E. N. Rasmussen, and D. O. Blanchard, 1998: Variability of storm-relative helicity during VORTEX. Mon. Wea. Rev., 126, 2959-2971.

- C. Hannon, J. Frame, E. Lancaster, A. Pietrycha, R. Edwards, and R. L. Thompson, 2003: Characteristics of vertical wind profiles near supercells obtained from the Rapid Update Cycle. Wea. Forecasting, 18, 1262-1272.

Marwitz, J. D., 1972: The structure and motion of severe hailstorms. Part I: Supercell storms. J. Appl. Meteor., 11, 166-179.

Moller, A. R., C. A. Doswell III, and R. Przybylinski, 1990: Highprecipitation supercells: A conceptual model and documentation. Preprints, 16th Conf. on Severe Local Storms, Kananaskis Park, AB, Canada, Amer. Meteor. Soc., 52-57.

Monteverdi, J. P., W. Blier, G. Stumpf, W. Pi, and K. Anderson, 2001: First WSR-88D documentation of an anticyclonic supercell with anticyclonic tornadoes: The Sunnyvale-Los Altos, California, tornadoes of 4 May 1998. Mon. Wea. Rev., 129, 2805-2814.

Rasmussen, E. N., and D. O. Blanchard, 1998: A baseline climatology of sounding-derived supercell and tornado forecast parameters. Wea. Forecasting, 13, 1148-1164.

Rotunno, R., and J. B. Klemp, 1982: The influence of the shearinduced pressure gradient on thunderstorm motion. Mon. Wea. Rev., 110, 136-151.

_ and - 1985: On the rotation and propagation of simulated supercell thunderstorms. J. Atmos. Sci., 42, 271-292.

Sills, D. M., J. Wilson, P. I. Joe, D. W. Burgess, R. M. Webb, and N. I. Fox, 2004: The 3 November tornadic event during Sydney 2000: Storm evolution and the role of low-level boundaries. Wea. Forecasting, 19, 22-42.

Stumpf, J., A. Witt, D. E. Mitchell, P. L. Spencer, J. T. Johnson, M. D. Eilts, K. W. Thomas, and D. W. Burgess, 1998: The National Severe Storms Laboratory Mesocyclone Detection Algorithm for the WSR-88D. Wea. Forecasting, 13, 304-326.

Thompson, R. L., 1998: Eta Model storm-relative winds associated with tornadic and nontornadic supercells. Wea. Forecasting, 13, 125-137.

Wand, M. P., and M. C. Jones, 1995: Kernel Smoothing. Statistics and Applied Probability Monogr., No. 60, Chapman and Hall, $212 \mathrm{pp}$.

Weaver, J. F., 1979: Storm motion as related to boundary-layer convergence. Mon. Wea. Rev., 107, 612-619.

Weisman, M. L., and J. B. Klemp, 1984: The structure and classification of numerically simulated convective storms in directionally varying wind shears. Mon. Wea. Rev., 112, 24792498.

_ M. S. Gilmore, and L. J. Wicker, 1998: The impact of convective storms on their local environment: What is an appropriate ambient sounding? Preprints, 19th Conf. on Severe Local Storms, Minneapolis, MN, Amer. Meteor. Soc., 238-688.

Wilks, D. S., 1995: Statistical Methods in the Atmospheric Sciences. Academic Press, 467 pp.

Zehr, R. M., and J. F. W. Purdom, 1982: Examples of a wide variety of thunderstorm propagation mechanisms. Preprints, 12th Conf. on Severe Local Storms, San Antonio, TX, Amer. Meteor. Soc., 499-502. 